Article

\title{
Functional, Biophysical, and Structural Characterization of Human IgG1 and IgG4 Fc Variants with Ablated Immune Functionality
}

\author{
Susan H. Tam * (i), Stephen G. McCarthy *, Anthony A. Armstrong, Sandeep Somani, \\ Sheng-Jiun Wu, Xuesong Liu, Alexis Gervais, Robin Ernst, Dorina Saro, Rose Decker, \\ Jinquan Luo, Gary L. Gilliland, Mark L. Chiu * and Bernard J. Scallon \\ Janssen Research \& Development, LLC, 1400 McKean Road, Spring House, Ambler, PA 19477, USA; \\ aarmst12@its.jnj.com (A.A.A.); ssomani@its.jnj.com (S.S.); swu4@its.jnj.com (S.-J. W.); xliu8@its.jnj.com (X.L.); \\ agervais@its.jnj.com (A.G.); rernst2@its.jnj.com (R.E.); dsaro@its.jnj.com (D.S.); rdecker5@its.jnj.com (R.D.); \\ jluo@its.jnj.com (J.L.); ggillila@its.jnj.com (G.L.G.); bhscallon@gmail.com (B.J.S.) \\ * Correspondence: susanhtam@gmail.com (S.H.T.); sgmcc0711@gmail.com (S.G.M.); mchiu@its.jnj.com (M.L.C.); \\ Tel.: +1-610-299-7994 (S.H.T); +1-610-836-2569 (S.G.M.); +1-610-651-6862 (M.L.C.)
}

Received: 19 July 2017; Accepted: 21 August 2017; Published: 1 September 2017

\begin{abstract}
Engineering of fragment crystallizable ( $\mathrm{Fc}$ ) domains of therapeutic immunoglobulin (IgG) antibodies to eliminate their immune effector functions while retaining other Fc characteristics has numerous applications, including blocking antigens on $\mathrm{Fc}_{\mathrm{c}}$ gamma (Fc $\gamma$ ) receptor-expressing immune cells. We previously reported on a human IgG2 variant termed IgG2 $\sigma$ with barely detectable activity in antibody-dependent cellular cytotoxicity, phagocytosis, complement activity, and Fc $\gamma$ receptor binding assays. Here, we extend that work to IgG1 and IgG4 antibodies, alternative subtypes which may offer advantages over IgG2 antibodies. In several in vitro and in vivo assays, the IgG1 $\sigma$ and $\operatorname{IgG} 4 \sigma$ variants showed equal or even lower Fc-related activities than the corresponding IgG2 $\sigma$ variant. In particular, IgG1 $\sigma$ and IgG4 $\sigma$ variants demonstrate complete lack of effector function as measured by antibody-dependent cellular cytotoxicity, complement-dependent cytotoxicity, antibody-dependent cellular phagocytosis, and in vivo T-cell activation. The IgG1 $\sigma$ and IgG4 $\sigma$ variants showed acceptable solubility and stability, and typical human IgG1 pharmacokinetic profiles in human FcRn-transgenic mice and cynomolgus monkeys. In silico T-cell epitope analyses predict a lack of immunogenicity in humans. Finally, crystal structures and simulations of the IgG1 $\sigma$ and IgG4 $\sigma$ Fc domains can explain the lack of Fc-mediated immune functions. These variants show promise for use in those therapeutic antibodies and Fc fusions for which the Fc domain should be immunologically "silent".
\end{abstract}

Keywords: Fc engineering; silent effector function; IgG1; IgG2; IgG4; IgG sigma; developability; pharmacokinetics; crystal structure

\section{Introduction}

The biological functionality of therapeutic antibodies depends on the interactions of two regions of the protein with components of its external environment: the antigen binding region (Fab) interacting with an antigen, and the fragment crystallizable $(\mathrm{Fc})$ region interacting with components of the immune system. The Fc region of the immunoglobulin (IgG) antibody, which is the focus of this study, can have interactions with $\mathrm{Fc}_{\mathrm{c}}$ gamma receptors $(\mathrm{Fc} \gamma \mathrm{R})$ and first subcomponent of the $\mathrm{C} 1$ complex $(\mathrm{C} 1 \mathrm{q})$ that mediate antibody-dependent cellular cytotoxicity (ADCC), complement-dependent cytotoxicity (CDC), antibody-dependent cellular phagocytosis (ADCP), induction of secretion of mediators, endocytosis of opsonized particles, as well as modulation of tissue and serum half-life through interaction with the neonatal $F_{c}$ receptor $\left(F_{C} R n\right)[1,2]$. Numerous publications have reviewed the application of enhanced 
Fc effector function to increase biologic activity [3-6]. In addition, the coupling of the Fab and Fc regions can impact the therapeutic window for safety and efficacy of antibodies and Fc fusion proteins $[3,7]$.

Fc-mediated effector functions are best avoided for some applications such as systemic neutralization of cytokines, targeting cell surface antigens on immune cells, or when engineering bispecific molecules to bring target diseased cells within proximity of effector immune cells to provide a more specific immune receptor engagement $[3,8,9]$. In each of these cases, it is best not to stimulate unwanted cell and tissue damage or risk undesired effector cell activation, immune cell depletion, or Fc $\gamma \mathrm{R}$ cross-linking that might induce cytokine release through engagement of Fc-mediated effector functions [3]. An important consideration in such biological processes is that the complexity of Fc $\gamma \mathrm{R}$ functional properties is increased by the varying densities of activating and inhibitory receptors on the different effector cell populations [10]. Likewise, since the threshold of activation can be variable with different patients, it would be prudent for safety considerations to develop antibodies with a more silent Fc framework. Thus, development of completely silent FC domains can be critical for biologics that do not require $\mathrm{Fc} \gamma \mathrm{R}$ or $\mathrm{C} 1 \mathrm{q}$ mediated effector functions [11].

When an antibody with no effector function is required, there are different approaches one may take to generate a molecule with the desired properties. Unfortunately, results of some strategies often come with liabilities to the molecular profile. For instance, Fab or $\mathrm{F}\left(\mathrm{ab}^{\prime}\right)_{2}$ fragments can be generated; however, such molecules have shorter half-lives in patient sera. Chemical modifications can extend the half-life of such molecules, but can also bring potential risks with toxicities [12]. Another strategy has been to eliminate the $\mathrm{N}$-linked glycosylation at residue Asparagine 297 (European Union (EU) numbering) [13-16]; however, this can reduce antibody solubility and stability. Another approach employs mutagenesis of specific Fc amino acid residues to specifically influence effector functions [17].

An example of this approach is illustrated in the first marketed therapeutic antibody (Orthoclone OKT3, a murine IgG2a) in which two mutations in the lower hinge (L324A/L235A, referred to as AA) were introduced to mitigate the induction of cytokine storm $[18,19]$. Also, because Fc $\gamma$ Rs are highly selective in subclass specificity and affinity $[20,21]$, another approach may be to move the Fab domains onto Fc regions which elicits less effector function such as human IgG2 (huIgG2) or IgG4 (huIgG4) [22]. In addition, swapping among the sequences of the four human IgG (huIgG) subtypes has been used to design more silent Fc domains [3,4,23-25] that have resulted in such variants as huIgG2/4 [26], huIgG2m4 [27], and L234F/L235E/P331S (FES) [28]. Notably, Vafa and co-workers employed multiple strategies to develop a huIgG2 variant, termed huIgG2 sigma (IgG2 $\sigma$ ) that showed undetectable Fc-mediated effector function and C1q binding [29]. In utilizing such strategies for silencing Fc effector function, it needs to be recognized that there is some potential for huIgG2 subtype molecules to form heterogeneous isoforms which can be a challenge in the generation of a homogeneous product [30-32].

Although huIgG4 has weak binding affinity to most Fc $\gamma$ Rs except for the high affinity receptor Fc $\gamma$ RI, it does retain the ability to induce phagocytosis by macrophages (expressing Fc $\gamma$ RI, Fc $\gamma$ RIIa, and F( $\gamma$ RIIIa) and possibly activate monocytes when in an immune complex due to activating Fc $\gamma$ Rs on specific immune cells. Recent additional approaches to generate antibodies with no effector function have included disruption of proline sandwich motifs [33], and incorporation of asymmetric charged mutations in the lower hinge or constant heavy chain domain $2\left(\mathrm{C}_{\mathrm{H}} 2\right)$ domain [34]. Because development of antibodies with silent $\mathrm{FC}_{\mathrm{C}}$ domains continues to be important for various therapies, and because the threshold of activation may be different for each patient or disease population, efforts are on-going to obtain the most silent Fc variants which will have improved safety and good manufacturing qualities.

We describe here the functional and structural characteristics of three novel silent Fc designs:

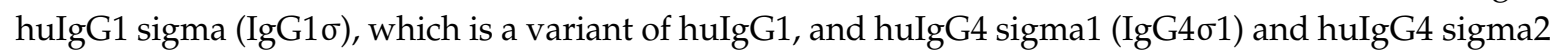
$(\operatorname{IgG} 4 \sigma 2)$, which are variants of huIgG4. The effector functions of these silent Fc variants are compared to those of previously described constructs such as huIgG1 L234A/L235A (AA) [25], huIgG4 S228P/L234A/L235A (PAA) [19,35], and huIgG1 L234F/L235E/P331S (FES, a triple mutant 
being employed in a clinical anti-interferon receptor antibody [36]). We also present a comparison of serum half-lives in mice and cynomolgus monkeys, an evaluation of potential immunogenicity, and an assessment of biophysical stability. Crystal structures and molecular modeling were carried out to understand the mechanism for lack of interactions between the IgG variants and the Fc gamma receptors. The aim of the studies presented here is to provide data on the biological, biophysical,

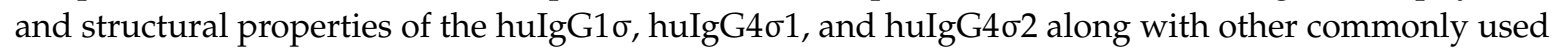
silent Fc formats to enable development of better quality antibody therapeutics.

\section{Results}

\subsection{Design of Silent Fc HuIgGs}

Silent human IgG Fcs were designed by uniquely combining the sequence from previously characterized variants having mutations in the hinge and $\mathrm{C}_{\mathrm{H}} 2$ regions [29]. Mutations present in these variants are listed in Figure 1 and Table 1. All sequences described follow the EU numbering system [37,38].

Both huIgG1 $\sigma$ and the huIgG2 $\sigma$ constructs contain a total of seven mutations in their hinge and $\mathrm{C}_{\mathrm{H}} 2$ domains (Figures 1 and 2; Table 1). However, only six of the mutations are common to both huIgG2 $\sigma$ and the huIgG1 $\sigma$ variant described here. HuIgG1 $\sigma$ uniquely includes an L234A mutation, and huIgG2 $\sigma$ has a V309L mutation. HuIgG1 naturally has a leucine at that position.

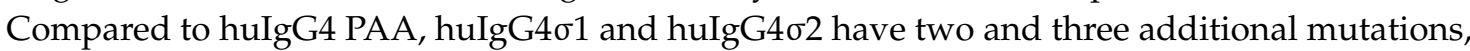
respectively, for a total of five and six mutations (Table 1). While modeled after huIgG2 $\sigma$, these huIgG4 variants do not have the full set of sigma mutations present in huIgG2 $\sigma$ because the huIgG4 sequence naturally contains four of those residues.
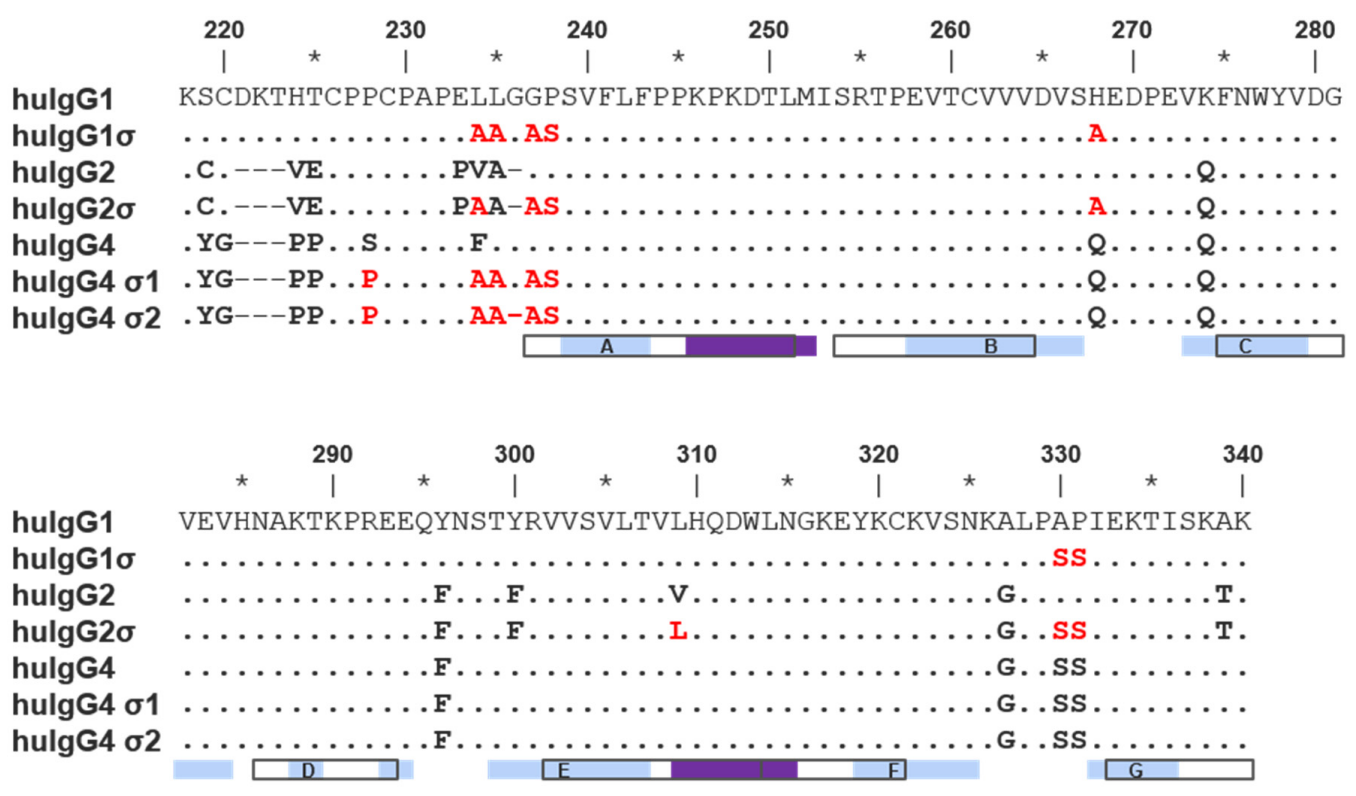

Figure 1. Alignment of hinge and constant heavy chain domain $2\left(\mathrm{C}_{\mathrm{H}} 2\right)$ domain amino acid sequences of wild-type human immunoglobulin G1 (IgG1), IgG2 and IgG4 as well as their sigma variants. The alignment above uses EU numbering. Residues identical to wild-type IgG1 are indicated as dots; gaps are indicated with hyphens. Sequence is given explicitly if it differs from wild-type IgG1 or from the parental subtype for $\sigma$ variants. In the latter case, sequence is colored red. Open boxes beneath the alignment correspond to International Immunogenetics Information System (IMGT) strand definitions (labeled) [39]. Light blue and purple boxes beneath the alignment correspond to the strand and helix secondary structure assignment for wild-type IgG1 in the Protein Data Bank (PDB) 3AVE (chain A) [40]. Residues 267-273 form the BC loop and 322-332 form the FG loop. 


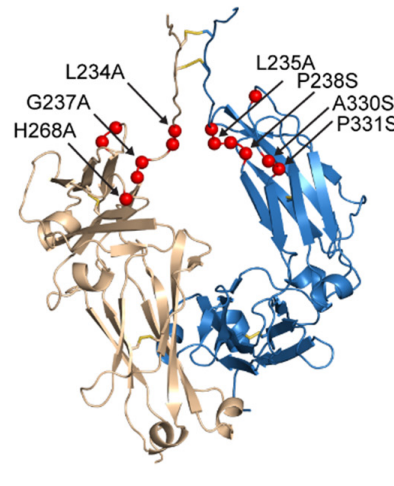

$\lg G 1 \sigma$

A

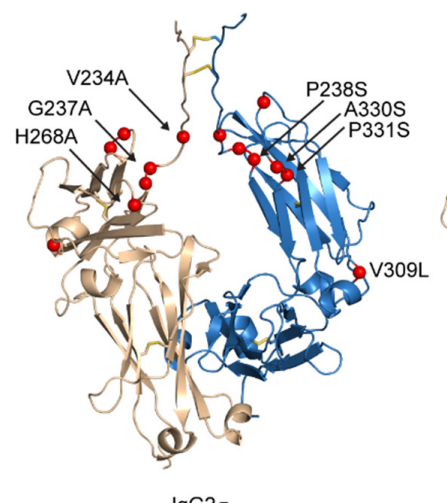

$\lg G 2 \sigma$

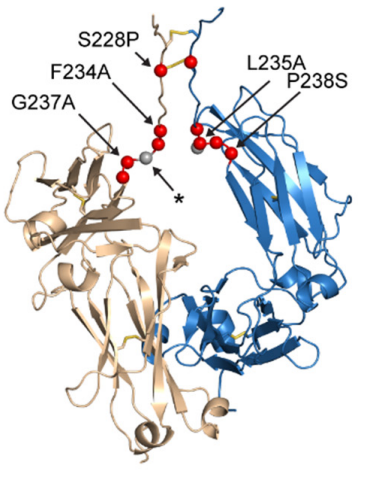

IgG4 PAA $\sigma 1 / 2$

B

C

Figure 2. Schematic indicating positions of mutations on generic Fc structure. Positions mutated relative to parental subtype are depicted as red spheres on a structure of $\mathrm{IgG1} \mathrm{FC}_{\mathrm{C}}$ having an idealized hinge (wheat and blue, cartoon) for $\operatorname{IgG} 1 \sigma(\mathbf{A}), \operatorname{IgG} 2 \sigma(\mathbf{B})$, and $\operatorname{IgG} 4 \sigma 1 / 2$ (C). For clarity, the sites of

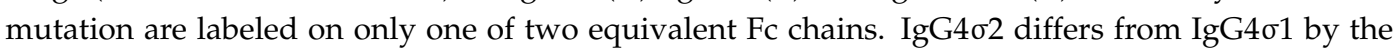
deletion of G236 (position indicated with a small, grey sphere and labeled with an asterisk).

Table 1. List of mutations in the hinge and constant heavy chain domain $2\left(\mathrm{C}_{\mathrm{H}} 2\right)$ regions of different silent immunoglobulin (IgG) designs.

\begin{tabular}{|c|c|c|c|c|c|c|c|}
\hline & IgG1 AA & $\operatorname{IgG1\sigma }$ & IgG1 FES & $\operatorname{IgG} 2 \sigma$ & IgG4 PAA & $\operatorname{IgG4\sigma 1}$ & IgG4\%2 \\
\hline Core hinge & & & & & S228P & S228P & S228P \\
\hline \multirow{5}{*}{ Lower hinge } & L234A & L234A & L234F & V234A & F234A & F234A & F234A \\
\hline & L235A & L235A & L235E & & L235A & L235A & L235A \\
\hline & & & & & & & $\Delta \mathrm{G} 236$ \\
\hline & & G237A & & G237A & & G237A & G237A \\
\hline & & $\mathrm{P} 238 \mathrm{~S}$ & & $\mathrm{P} 238 \mathrm{~S}$ & & $\mathrm{P} 238 \mathrm{~S}$ & P238S \\
\hline \multirow{4}{*}{$\mathrm{C}_{\mathrm{H}} 2$ domain of $\mathrm{Fc}$} & & $\mathrm{H} 268 \mathrm{~A}$ & & $\mathrm{H} 268 \mathrm{~A}$ & & & \\
\hline & & & & V309L & & & \\
\hline & & A330S & & A330S & & & \\
\hline & & P331S & P331S & P331S & & & \\
\hline
\end{tabular}

$\overline{\Delta \text { Indicates deletion of residue. European Union (EU) numbering is used for the amino acid substitutions. }}$

\subsection{Fc $\gamma R$ Binding and Competition}

Since effector functions such as ADCC and ADCP are induced by the binding of antibody Fc with the various Fc $\gamma$ Rs on the surface of different immune cell types, it is crucial to minimize and if possible to eliminate this engagement. Testing for binding of the assorted Fc variants to human Fc $\gamma$ Rs was determined using an AlphaScreen competitive binding assay. The AlphaScreen competition strategy involves the following: biotin-labeled huIgG is captured on streptavidin donor beads; His-tagged Fc $\gamma$ Rs are captured on nickel acceptor beads; unlabeled competitor (test) antibodies are applied as serial dilutions. There is a reduction in (maximal) signal when competition takes place. To provide an avidity component comparable to that created by multiple antibodies bound to a cell surface, the test antibodies were cross-linked with anti- $\mathrm{F}\left(\mathrm{ab}^{\prime}\right)_{2}$. This method increases the sensitivity of the assay to aid in confirming low-level binding.

Competitive binding analyses of Ab1 (anti-tumor necrosis factor (TNF) $\alpha$ huIgG1) samples to the different $\mathrm{Fc} \gamma \mathrm{Rs}$ are shown in Figure 3. On CD64 receptor (Fc $\gamma \mathrm{RI}), \mathrm{Ab} 1$ huIgG1 wild-type (WT) binds well with 50\% inhibition at approximately $1 \mu \mathrm{g} / \mathrm{mL}$. HuIgG1 AA and huIgG1 FES show low level binding at $500 \mu \mathrm{g} / \mathrm{mL}$, the highest concentration tested. However, the huIgG1 $\sigma$,

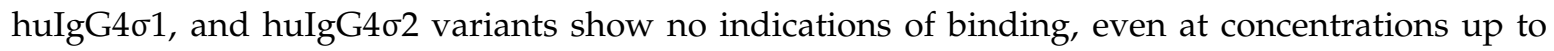


$1 \mathrm{mg} / \mathrm{mL}$ (Figure 3A). On CD32a (huFc $\gamma$ RIIa-H131 high and huFc $\gamma$ RIIa-R131 low affinity variants), CD32b (huFc $\gamma$ RIlb), and CD16a (huFc $\gamma$ RIIIa), the huIgG1 AA and huIgG1 FES variants showed varying degrees of binding to these receptors, yet the sigma $(\sigma)$ variants showed complete lack of binding compared to the huIgG1 wild-type (WT) (Figure 3B-E). HuIgG4 PAA was not included in this test panel due to reagent constraints, but huIgG4 PAA has been reported to have reduced, but not eliminated binding to $\mathrm{Fc} \gamma \mathrm{Rs}[29,33]$. These collective data demonstrated that complexes formed from the IgG1 $\sigma$ and IgG4 $\sigma$ variants did not bind to Fc $\gamma$ Rs even at high concentrations.
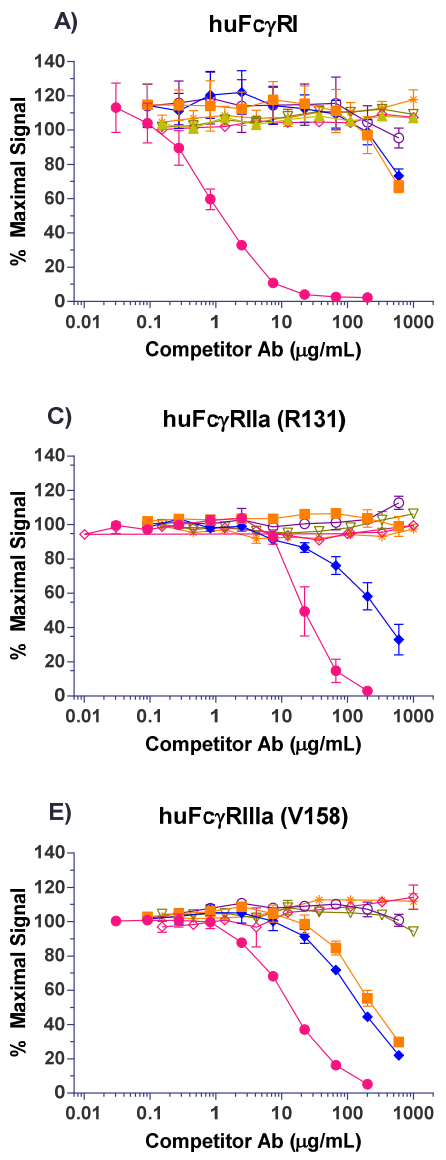
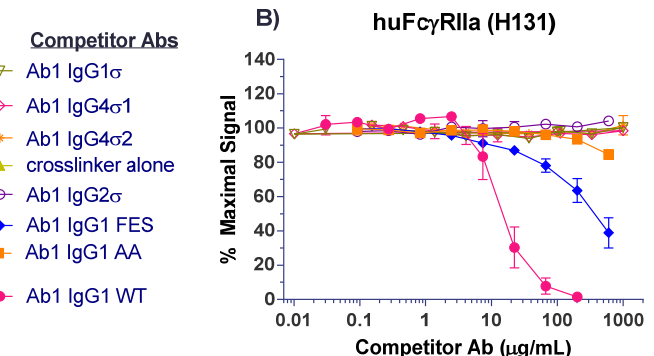

Competitor Abs

- $\mathrm{Ab} 1 \lg \mathrm{G} 2 \sigma$

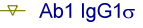

$\diamond$ Ab1 lgG4 o1

* Ab1 IgG4 $\sigma 2$

- Ab1 IgG1 AA

$\rightarrow$ Ab1 IgG1 FES

$\rightarrow$ Ab1 lgG1 WT

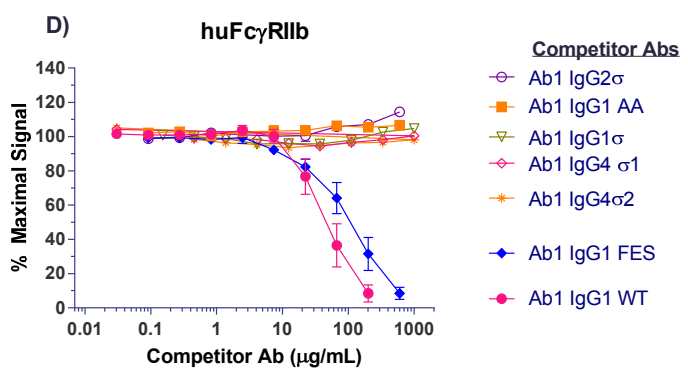

Figure 3. Testing for interactions of cross-linked huIgG variants with Fc $\gamma$ receptors. Binding of huIgG Ab1 (anti-TNF $\alpha$ ) molecules to human Fc $\gamma$ Rs was assessed using AlphaScreen bead assays in a competitive format. To increase sensitivity of the assays, test samples were cross-linked to introduce binding avidity by using a goat $\mathrm{F}\left(\mathrm{ab}^{\prime}\right)_{2}$ anti-huIgG $\mathrm{F}\left(\mathrm{ab}^{\prime}\right)_{2}$-specific fragment in 1:1 molar ratio with the test antibodies. Cross-linked test antibodies at the designated concentrations were co-incubated with biotin-labeled huIgG Fc fragment (to avoid binding to cross-linker), the respective His-tagged Fc $\gamma$ Rs, nickel chelate acceptor beads, and streptavidin donor beads. Plates were read on the EnVision multi-label plate reader, and data plotted with GraphPad Prism v6.0 software. Shown are binding of cross-linked huIgG variants to: (A) huFc $\gamma$ RI, (B) huFc $\gamma$ RIIa-H131, high affinity allotype, (C) huFc $\gamma$ RIIa-R131, low affinity allotype, (D) huFc $\gamma$ RIIb, (E) huFc $\gamma$ RIIIa-V158, high affinity allotype. Non-binding of cross-linker alone is shown with the high affinity huFc $\gamma$ RI. All points represent the mean of duplicate samples \pm range. The plot labels refer to IgG1 AA—human IgG1 L234A/L235A; IgG1 FES—human IgG1 L234F/L235E/P331S; and IgG1 WT—wild type human IgG1. 


\subsection{Target Mediated Effector Function In Vitro}

\subsubsection{Antibody-Dependent Cell-Mediated Cytotoxicity (ADCC)}

When the $\mathrm{Fc}_{\mathrm{c}}$ region of an antibody binds to $\mathrm{Fc} \gamma \mathrm{R}$ on immune cells, cytotoxic factors are released causing ADCC and death of target cells, whose membrane-surface antigens have been bound by the specific antibody. To compare cytotoxic potential of the silent Fc variants, $\mathrm{K} 2$ cells (T72-18, TNF $\alpha \mathrm{SP} 2 / 0$ ) expressing the $\Delta 1-12$ variant of human TNF $\alpha$ were used as target cells and human peripheral mononuclear cells (PBMCs) were the immune effector cells in ADCC assays [41]. Figure 4 shows the combined data from six independent experiments that used PBMC effector cells from 15 different donors. Figure $4 \mathrm{~A}$ shows that Ab1 huIgG1 $\sigma$ and huIgG2 $\sigma$ have no cytotoxic activity compared to huIgG1 AA, huIgG1 FES variants and the positive control Ab1 huIgG1 WT.

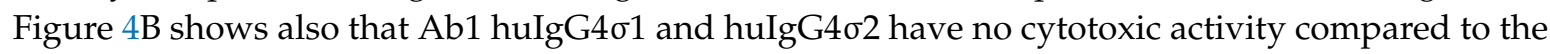

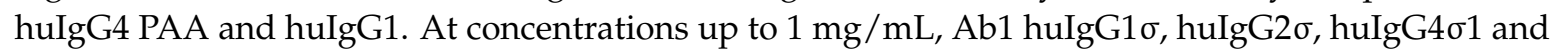
huIgG4\%2 showed minimal to no killing of target cells. In particular, the sigma variants displayed negligible cytotoxic activity at levels below that of the negative control Ab2 (anti-F glycoprotein of Respiratory Syncytial Virus a huIgG1) which did not bind to TNF $\alpha$. In this assay with numerous donors, Ab1 huIgG1 AA was the least silent Fc variant; HuIgG1 AA, huIgG1 FES, and huIgG4 PAA showed intermediate cytotoxic levels, and the most ADCC-silent molecules were the huIgG1 $\sigma$ and huIgG4 $\sigma$ variants.
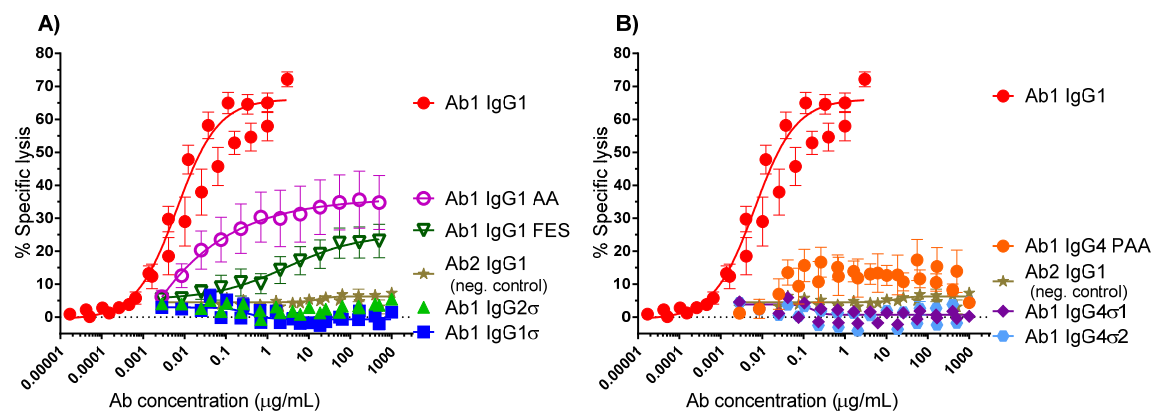

Figure 4. Antibody-dependent cellular cytotoxicity (ADCC) assays (combined data from six experiments). Titrating amounts of test antibodies (Abs) were added to K2 target cells, followed by addition of human PBMC immune effector cells. The extent of target cell lysis was quantitated after $2 \mathrm{~h}$. Samples were tested in duplicate for each individual experiment. In the combined data shown here, 15 donors were tested, and each point represents the mean value \pm standard error of the mean. \% Specific lysis is shown in (A) for IgG1 $\sigma$ compared to IgG1 AA, FES, and IgG2 $\sigma$; and in (B) for

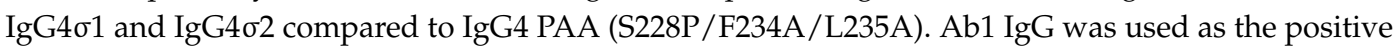
control and Ab2 IgG1 (neg. control) was the negative control.

\subsubsection{Antibody-Dependent Cellular Phagocytosis (ADCP)}

Binding of the Fc region to Fc $\gamma$ Rs on certain immune cells such as macrophages can cause cell death by phagocytosis. ADCP relies on macrophages to bind and devour target cells following antibody binding. To further evaluate the lack of effector function with the silent Fc variants, ADCP flow cytometric assays were performed using macrophages derived from primary human monocytes as effector cells and K2 cells as target cells. Macrophages and K2 cells were labeled with separate fluorescent dyes and co-cultured for $5 \mathrm{~h}$ in the presence of different concentrations of test antibody. Quantitation of antibody-opsonized target cells was measured by dual-label flow cytometry. Representative data from two experiments are shown in Figure 5. Ab1 huIgG1 shows approximately 30\% target cell killing by macrophages, whereas Ab1 huIgG4 PAA, Ab1 huIgG401, and Ab1 huIgG4\%2 show low level killing ( $<5 \%)$, comparable with that of Ab2 (non-TNF binding) 
IgG1 (Figure 5A). In another study, Ab huIgG1 shows a similar extent of cell killing by macrophages

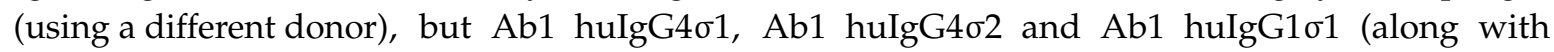
Ab1 huIgG2o, Ab1 huIgG4 PAA and Ab2 huIgG1 negative control) show minimal K2 target cell phagocytosis relative to positive and negative controls at concentrations up to $1 \mathrm{mg} / \mathrm{mL}$ (Figure 5B). These results suggest that the huIgG1 $\sigma$ and huIgG4 $\sigma$ variants would not have Fc-mediated cytotoxic potential when bound to target immune cells.
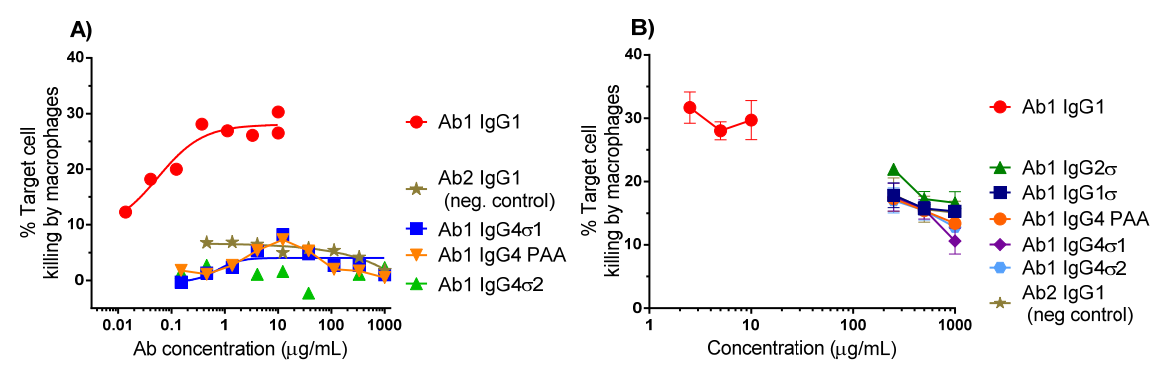

Figure 5. Antibody-Dependent Cellular Phagocytosis (ADCP) (phagocytosis) assays. The extent of phagocytosis was measured using flow cytometry. (A) A representative experiment, showing the \%Target cell killing by macrophages in a $5 \mathrm{~h}$ assay with different concentrations of test antibodies; (B) Results using macrophages from a different donor tested in triplicate with a focus on high Ab concentrations $(200-1000 \mu \mathrm{g} / \mathrm{mL})$. \% Target cell killing is the number of dual-labeled cells (target cells engulfed by macrophages) divided by total number of target cells $\times 100$. Error bars represent \pm standard error of the mean.

\subsubsection{Complement-Dependent Cytotoxicity (CDC)}

Complement-dependent cell killing occurs when the Fc portion recruits serum complement proteins to the cell bound by the specific antibody; leading to induction of a membrane attack complex and target cell lysis. To determine whether the Fc variants have complement activation capability, CDC assays were performed using $\mathrm{K} 2$ target cells, rabbit complement and a panel of Ab1 huIgG Fc variants.

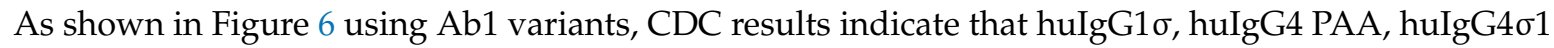

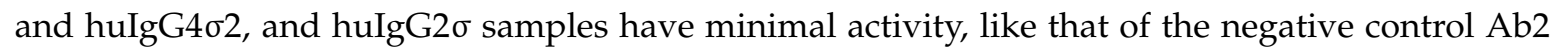
huIgG1 at concentrations up to $500 \mu \mathrm{g} / \mathrm{mL}$. In contrast to the negative control, the positive control Ab1 huIgG1 has measurable target mediated specific killing activity at less than $0.1 \mu \mathrm{g} / \mathrm{mL}$. Relative to these controls, Ab1 huIgG1 AA and huIgG1 FES show intermediate levels of cytotoxicity. Data indicate that

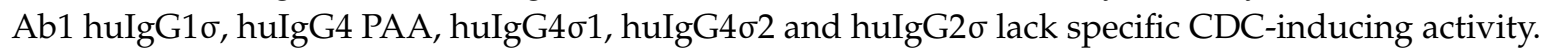

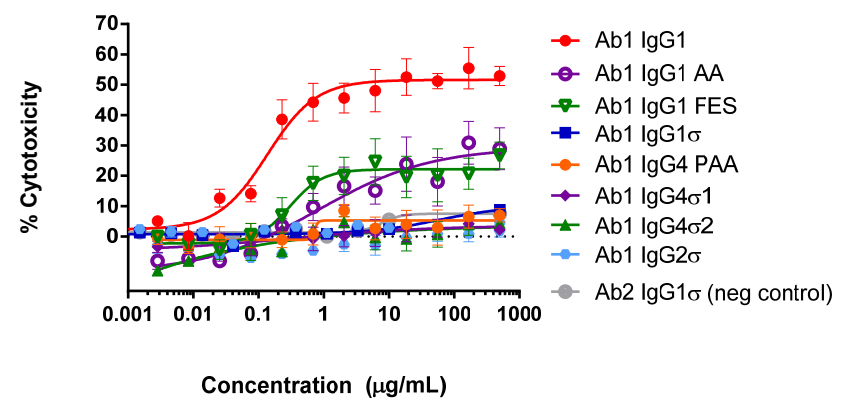

Figure 6. Cell-based CDC assays with IgG Fc variants. K2 mouse myeloma cells stably expressing a transmembrane form of human tumor necrosis factor alpha (TNF $\alpha$ ) were incubated with varying concentrations of test antibody and rabbit complement, and then cell viability was measured by detecting lactate dehydrogenase release in the culture supernatant. Error bars represent standard error of the mean from samples analyzed in triplicate. Ab2 IgG1 $\sigma$ does not bind to target cells and is the negative control antibody. 


\subsection{FcRn Binding}

Interaction with neonatal $\mathrm{Fc}_{\mathrm{c}}$ receptor $\left(\mathrm{F}_{\mathrm{C}} \mathrm{Rn}\right)$ is a critical factor that contributes to sustaining circulating antibody half-life [2], thus better binding to $\mathrm{FcRn}$ is expected to give a longer antibody half-life. To determine whether the sigma Fc mutations affect FcRn binding, competition binding by an enzyme-linked immunosorbent assay (ELISA) was performed with varying concentrations of unlabeled silent Fc antibody and a fixed amount of biotin-labeled huIgG1 on plate-bound human FcRn at $\mathrm{pH}$ 6. Bound tracer antibody was determined by colorimetric detection after incubation with streptavidin-horseradish peroxidase (HRP) and tetramethylbenzidine (TMB) substrate reagents. ELISA results shown in Figure 7 indicate a slight (less than 2-fold) reduction in binding affinity to FcRn for huIgG1 $\sigma$ relative to the huIgG1 wild-type control. Other tested variants show up to 4 -fold reductions in relative affinity. The negative control variant (huIgG1 H435A) of Ab2 appropriately shows no binding to FcRn. While these findings indicate some reduction in relative affinity for the variants tested, all the silent Fc variants can bind FcRn, and huIgG1 $\sigma$ appears to bind FcRn the best.
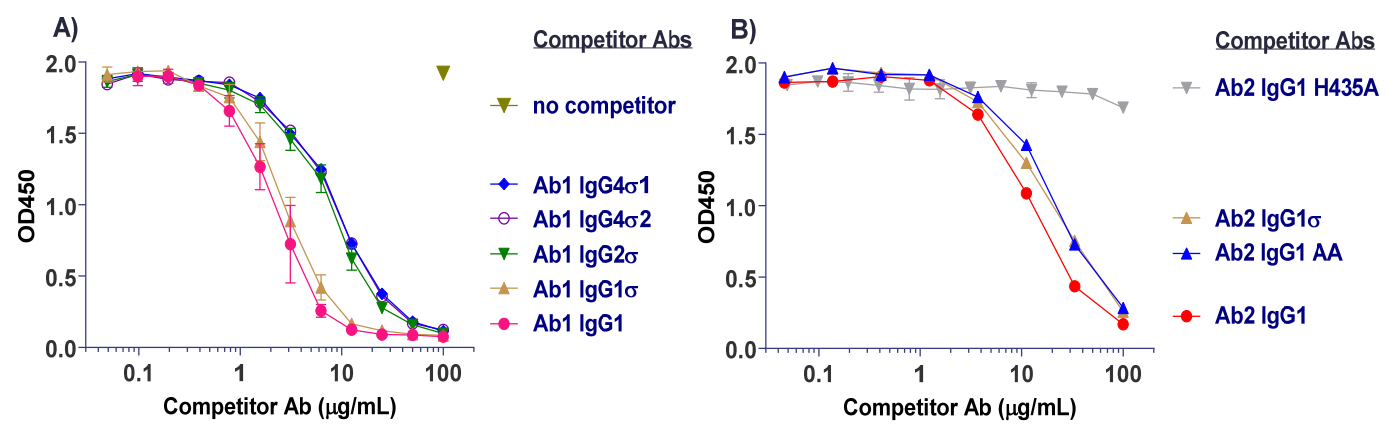

Figure 7. Binding of IgG variants to neonatal Fc receptor (FCRn). In a competition binding format, titrating amounts of antibody were combined with a fixed concentration $(4 \mu \mathrm{g} / \mathrm{mL})$ of biotin-labeled huIgG1. Antibody mixtures were incubated with immobilized human FcRn on a plate for $1 \mathrm{~h}$, washed, detected with streptavidin-horseradish peroxidase (HRP), and developed with tetramethylbenzidine (TMB) substrate. Bound tracer antibody was detected via absorbance at $450 \mathrm{~nm}$ measured on a plate reader. (A) Ab1 samples and (B) Ab2 samples were tested in duplicate and error bars represent mean \pm range.

\subsection{Fc $\gamma$ R Binding Interactions In Vivo}

\subsubsection{T Cell Immunostimulatory Activity}

In vivo, the $F_{c}$ and $F_{c} \gamma R$ interaction can be evaluated and detected by $\mathrm{T}$ cell activation [42]. Human $\mathrm{Fc} \gamma \mathrm{R}$ transgenic mice ( $\mathrm{F} c \gamma \mathrm{R}-\mathrm{hu})$ express all five human $\mathrm{Fc} \gamma \mathrm{Rs}$ and have no expression of endogenous mouse Fc $\gamma$ Rs [43]. When anti-mouse CD3 antibody $(\mathrm{Ab} 4,2 \mathrm{C} 11)$ binds to mouse T cells, there is an agonistic effect (presumably due to binding of $\mathrm{Fc} \gamma \mathrm{R}$ on neighboring cells at the same time it is bound to CD3 on T cells) which leads to up-regulation of activation markers such as CD69 and CD25 [42]. An increase in binding of Fc to Fc $\gamma$ R correlates with an increased level of T cell activation. This agonist activity was used to evaluate $\mathrm{T}$ cell activation of the $\mathrm{Fc}_{\mathrm{c}}$ variants in $\mathrm{Fc} \gamma \mathrm{R}$-hu mice.

An initial study was done to confirm that $\mathrm{T}$ cell activation in the Fc $\gamma \mathrm{R}-\mathrm{hu}$ mice is due to Fc $\gamma \mathrm{R}-\mathrm{Fc}$ binding. Three strains of mice with different gene dosages were used: the 5-transgene Fc $\gamma$ R-humanized mice, mice hemizygous for the 5 transgenes, and $\mathrm{FcR} \alpha$ chain null mice (Fc $\gamma \mathrm{R}$ knockouts). Ab4 huIgG1 and Ab4 huIgG1 $\sigma$ were injected into the intraperitoneal cavity $(0.5 \mathrm{mg} / \mathrm{kg}, 10 \mathrm{~mL} / \mathrm{kg})$. Approximately $24 \mathrm{~h}$ later, mice were euthanized and their spleens removed for $\mathrm{T}$ cell activation analyses by flow cytometry. Results demonstrated the dependence on the presence of human $\mathrm{Fc} \gamma \mathrm{R}$, since very little or no $\mathrm{T}$ cell activation using huIgG1 was detected in the null mice, an intermediate level of activation was detected in hemizygous mice, and the most robust activation was noted in the homozygous mice 
(Figure 8A). Low to no activation was observed in T cells of huIgG1 $\sigma$ treated mice. Next, homozygous Fc $\gamma$ R-humanized mice were used to explore a panel of Ab4 silent Fc variants. Twenty-four hours following the dose of the test antibodies, splenocytes from the mice were isolated and flow analyses performed to determine $\mathrm{T}$ cell levels of the early activation marker (CD69), and a late activation marker (CD25).

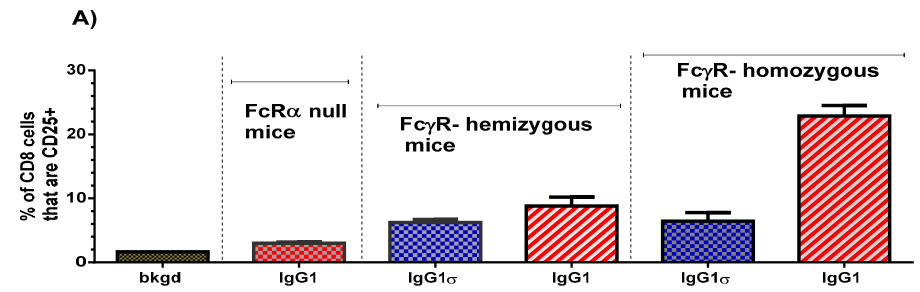

B)

CD69 activation

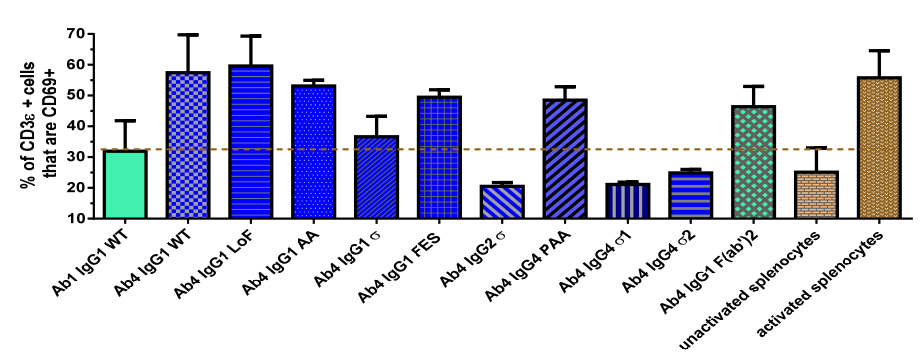

C)

CD25 activation

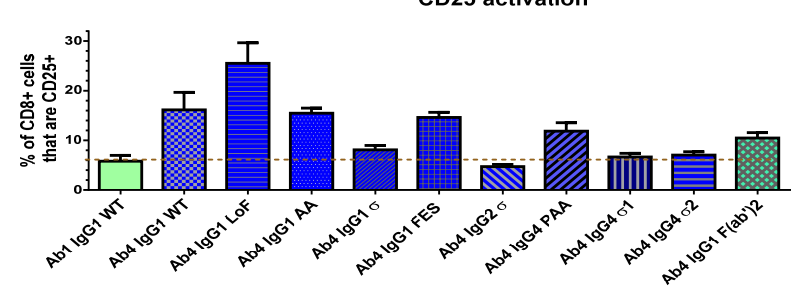

Figure 8. In vivo T cell activation. (A) Results of in vivo $\mathrm{T}$ cell activation by IgG1 $\sigma$ relative to wild-type IgG1. Fc $\gamma$ R-humanized mice, homozygous and hemizygous, and mice lacking Fc $\gamma$ Rs (null) were injected intraperitoneal with a $0.5 \mathrm{mg} / \mathrm{kg}$ dose of either human IgG1 $\sigma$ or wild-type IgG1. After $24 \mathrm{~h}$, spleens were collected from each mouse and the percent of CD8+ cells (as well as CD3e cells, not shown) that stained positive for CD25 was measured by flow cytometric analyses. (B) Comparison of in vivo T cell CD69 activation with panel of silent IgG Fc variants. (C) Comparison of in vivo T cell CD25 activation with panel of silent IgG Fc variants. The dashed line represents the level of non-specific activation, derived from the mean value of un-activated splenocytes and splenocytes treated with a control IgG1 WT. Error bars represent the standard error of mean from 3 to 6 samples in both studies.

Comparison of CD69 activation results (expressed as a percentage of CD3 $\varepsilon$ cells) are shown in Figure $8 \mathrm{~B}$ for the silent $\mathrm{FC}_{\mathrm{C}}$ variants, a non- $\mathrm{Fc} \gamma \mathrm{R}$ binding $\mathrm{F}\left(\mathrm{ab}^{\prime}\right)_{2}$ fragment and a non- $\mathrm{T}$ cell binding Ab1 huIgG1. Splenocytes from wild-type IgG (Ab4 huIgG1), low fucose IgG1 (Ab4 huG1 LoF with high affinity binding to CD16), and phorbol myristate acetate treated mice, collectively showed a robust CD69 signal (mean value $58 \%$ ) compared to un-activated splenocytes ( $25 \%$ ) from phosphate- buffered saline (PBS) treated mice. Ab4 $\mathrm{F}\left(\mathrm{ab}^{\prime}\right)_{2}$ gave a substantial unexpected signal $(46 \%)$ which suggested that $\mathrm{T}$ cells may have a low level of activation merely by bivalent $\mathrm{CD} 3$ binding without $\mathrm{F} c \gamma \mathrm{R}$ engagement. Ab4 huIgG1 induced a higher CD69 activation level than Ab1 huIgG1 WT because it has both CD3 and Fc $\gamma$ R engagement. The dashed line in Figure 8B represents a "non-specific activation" level $(29 \%)$, determined from the average value of untreated splenocytes and splenocytes treated with a non- $\mathrm{T}$ cell binding Ab1 huIgG1. Ab4 huIgG1 AA, Ab4 huIgG1 FES and Ab4 huIgG4 PAA produced an increase in 
$\mathrm{T}$ cell activation relative to the non-specific activation level. However, Ab4 huIgG2 $\sigma, \mathrm{Ab} 4 \mathrm{huG} 4 \sigma 1$ and Ab4 huG4o2 caused a decrease in CD69 activation relative to the non-specific level, and Ab4 huIgG1 $\sigma$ caused an activation level like that of the Ab1 huIgG1 WT which does not bind T cells.

CD25 activation levels of splenic T cells (expressed as a percent of CD8+ cells) from mice treated with the silent $\mathrm{Fc}$ variants are shown in Figure $8 \mathrm{C}$. The dashed line represents the level for non-specific activation derived from splenocytes treated with control Ab1 huG1 WT. Consistent with CD69 results, Ab4 huG1 AA, huG1 FES, and huG4 PAA produced an increase in CD25 activation levels that are comparable to that of Ab4 huG1 WT treated mice. As expected, the Ab4 huIgG1 LoF induced a higher CD25 activation signal. Likewise, Ab4 huG1 $\mathrm{F}\left(\mathrm{ab}^{\prime}\right)_{2}$ caused a higher CD25 activation than expected (such as in the case of CD69 activation) which may be due to bivalent CD3 binding,

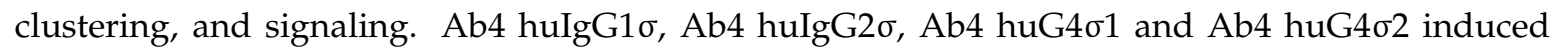
minimal CD25 activation. These in vivo CD69 and CD25 results indicated that binding of IgG1 $\sigma$,

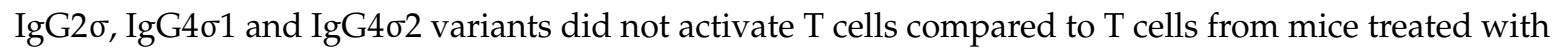
huIgG WT or huIgG4 PAA.

\subsubsection{Fc $\gamma$ R-Mediated Anti-Tumor Activity}

The B16 metastatic melanoma syngeneic model has been used to assess $\mathrm{Fc}$ and Fc $\gamma \mathrm{R}$ interactions. B16F10 mouse melanoma tumor cells can stimulate lung tumor metastasis, and murine TA99 antibody which targets the gp75 antigen on B16F10 cells, can inhibit tumor cell growth in mice [44,45]. Also, human TA99 antibody can inhibit metastasis, whereas a human IgG1 mutant which does not engage Fc $\gamma$ Rs has no effect in Fc $\gamma$ R-hu mice [43].

This B16 metastatic tumor model was used to test the effect of a huIgG1 $\sigma$ version of Ab5 (anti-grp75) on lung tumor metastasis in Fc $\gamma$ R-hu mice. These mice treated with different versions of Ab5: huIgG1, huIgG1 LoF (low fucose with enhanced ADCC, in-house data) and mIgG2a (mouse $\mathrm{Ab}$ as positive control) showed a significant reduction in lung tumor metastasis compared to the mice treated with PBS (Figure 9). Lung metastasis foci were decreased by 2-fold in mice treated with Ab5 mIgG2a or Ab5 huIgG1, and 3-fold with Ab5 huIgG1 LoF compared to the PBS treated mice. In contrast, mice treated with huIgG1 $\sigma$ showed no tumor inhibition, and although unexplained, huIgG1 $\sigma$ treated mice showed more tumor metastasis than the PBS treated mice. Results indicate that in vivo antibody-mediated tumor clearance appears to be dependent on binding to Fc $\gamma$ Rs by huIgG1 or huIgG1 LoF, whereas huIgG1 $\sigma$ which does not bind $\mathrm{Fc} \gamma \mathrm{R}$ is unable to prevent tumor cell growth.

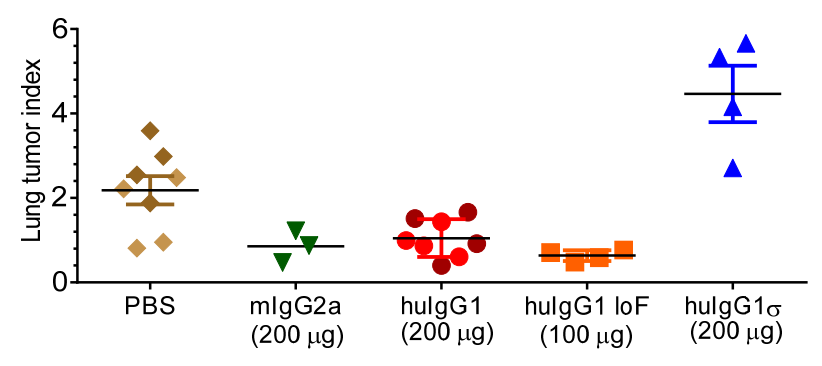

Figure 9. Effect of silent Fc mutations on syngeneic tumor cell metastasis. Fc $\gamma$ R-humanized mice were injected IV with B16F10 cells and received either: phosphate-buffered saline (PBS), Ab5 (TA99) mIgG2a, Ab5 huIgG1, Ab5 huIgG1 LoF (low fucose) or Ab5 huIgG1 $\sigma$ ( $n=4$ for groups) on days $0,2,4,7,9$ and 11 . On day 21 , lungs were harvested and metastasis foci were counted. Data show the mean number of lung metastasis foci expressed as lung tumor index from mice receiving the indicated treatment \pm standard error.

\subsection{Pharmacokinetics (PK)}

PK studies were done to determine whether normal antibody half-life would be altered using antibodies with silent sigma Fc mutations compared to the wild-type huIgG. Human FcRn transgenic 
mice ( $\operatorname{Tg} 32$ hemi, 8-10 weeks old, 3-4 per group) were intravenously-injected once with $2 \mathrm{mg} / \mathrm{kg}$ doses of the test antibody. Blood was collected at various times up to 35 days post-injection and sera prepared by standard procedure. A Meso Scale Discovery (MSD) assay using anti-human IgG specific reagents was employed for quantitating human IgG in the mouse serum samples. Terminal half-life values were obtained using a one-compartment linear fit using Prism 6.0 software (GraphPad, San Diego, CA, USA).

HuIgG serum concentrations over time for the mice are shown in Figure 10A. PK profiles display a linear decrease in IgG levels from day 7 through 35 . HuIgG2 $\sigma\left(t_{1 / 2}=5.5 \pm 0.5\right.$ days) shows a 2 -fold shorter half-life than the huIgG1 ( $t_{1 / 2}=11.4 \pm 1.7$ days). However, PK values for the other Fc variants: huIgG1 AA ( $\mathrm{t}_{1 / 2}=7.5 \pm 1.1$ days), huIgG4 PAA ( $\mathrm{t}_{1 / 2}=7.8 \pm 3.2$ days), huIgG4 $\sigma 2$ ( $\mathrm{t}_{1 / 2}=7.9 \pm 2.1$ days), huIgG4 $\sigma 1\left(\mathrm{t}_{1 / 2}=8.9 \pm 1.3\right.$ days), huIgG1 $\sigma\left(\mathrm{t}_{1 / 2}=9.6\right.$ days), huIgG2 ( $\mathrm{t}_{1 / 2}=11.2 \pm 0.8$ days $)$ and huIgG1 FES $\left(t_{1 / 2}=9.7 \pm 1.1\right.$ days) are not significantly different from that of huIgG1. These results indicate that the silent Fc mutations do not alter the PK compared to normal huIgG1, except for huIgG2 $\sigma$ which showed a reduction in half-life.

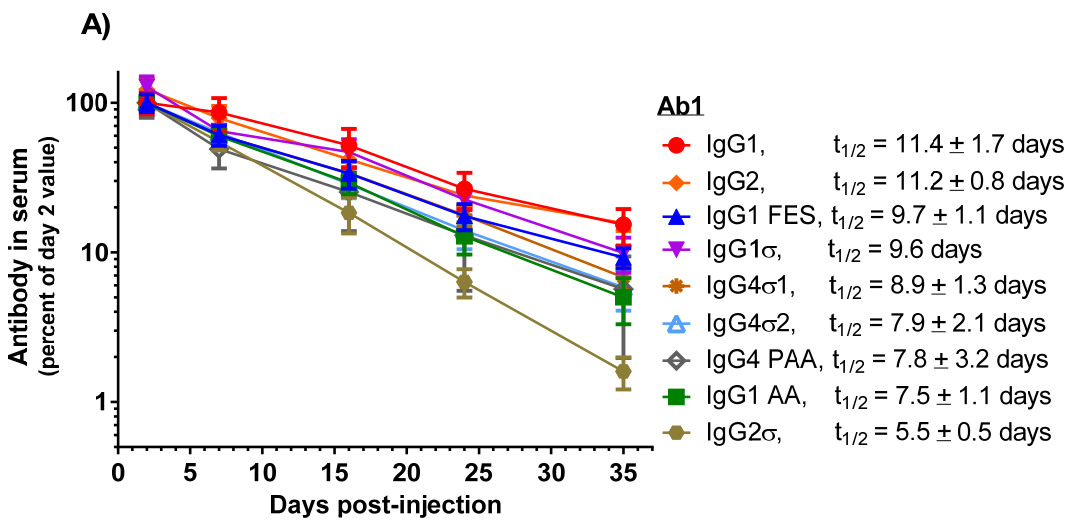

B)

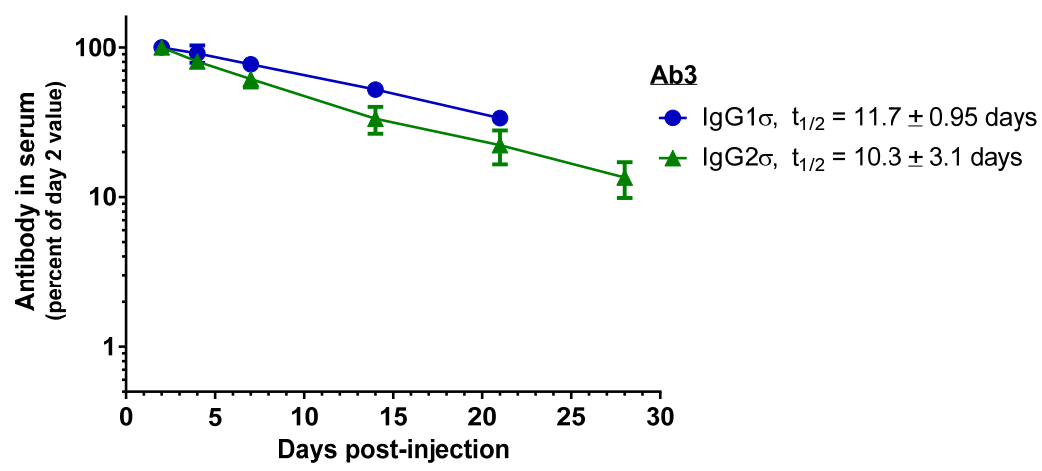

Figure 10. PK comparison of IgG1 WT and a panel of silent Fc variants in mice and cynomolgus monkeys. (A) Tg32 human FcRn transgenic mice were IV-injected with $2 \mathrm{mg} / \mathrm{kg}$ doses. Serum levels were expressed as a percent of day 2 values, the first timepoint. Data points represent the mean of 3 or 4 mice \pm SEM. (B) Cynomolgus monkeys were injected intravenously with $1.5 \mathrm{mg} / \mathrm{kg}$ dose of an $\operatorname{IgG} 2 \sigma$ version of Ab3 bispecific antibody and the mean PK profile was compared (in a separate study) with monkeys injected with $1.5 \mathrm{mg} / \mathrm{kg}$ of an huIgG1 $\sigma$ version of Ab3. Similarly, IgG1 $\sigma$ and IgG2 $\sigma$ versions of $\mathrm{Ab} 2 \times \mathrm{Ab} 5$ antibody were evaluated in the two separate studies.

PK studies in cynomolgus monkeys were conducted also to compare the huIgG1 $\sigma$ and huIgG2 $\sigma$ versions of Ab3, a bispecific antibody (anti-Respiratory Syncytial Virus (RSV)) and glycoprotein gp120 of HIV envelope, huIgG1). Male cynomolgus monkeys ( 2.5 to $3 \mathrm{~kg}, 3$ per groups) were intravenously injected once with $1.5 \mathrm{mg} / \mathrm{kg}$ of the test antibody. Blood samples were collected 
up to 21 days or 28 days, and PK analyzed as described. Although performed in separate studies, similar half-life values are observed for Ab3 huIgG1 $\sigma\left(t_{1 / 2}=11.7 \pm 0.95\right.$ days) and its huIgG2 $\sigma$ counterpart ( $\mathrm{t}_{1 / 2}=10.3 \pm 3.1$ days); and for Ab2 $\times$ Ab5 bispecific (anti-RSV $\times$ anti-gp75) huIgG1 $\sigma\left(t_{1 / 2}=5.6 \pm 0.5\right.$ days) and its huIgG2 $\sigma$ counterpart ( $t_{1 / 2}=5.2 \pm 0.1$ days) (Figure 10B). Considering that Ab2 huIgG1 historically has shown a half-life of 10-12 day in monkeys (Table S1), these monkey data along with the above mouse data, suggest that the huIgG1 $\sigma$ variant (as well as the

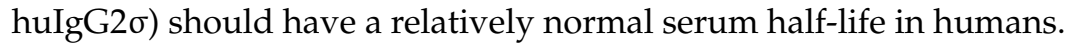

\subsection{Immunogenic Potential}

To assess the potential immunogenicity of huIgG1 and huIgG4 sigma variants, a T cell epitope analysis was done using the ImmunoFilter ${ }^{\mathrm{TM}} \mathrm{v} 2.7$ human leukocyte antigen (HLA) class II-peptide binding prediction software (Xencor, Inc., Monrovia, CA, USA) to predict potential immunogenicity in humans. These analyses generate IScores, which are weighted, population-relevant values that enable separation of individual 9-mer agretopes into groups by predicted immunogenic risk (PIR). Higher IScores indicate a higher PIR. Areas of sequence in the Fc variants which are identical to that of huIgG1 WT Fc sequence are excluded by the application of a tolerance threshold. IScores are averaged across all HLA-class II loci for each sequence of interest to create a single average IScore value. As shown in Figure 11A, the average IScores of the tested variant sequences are like those of their respective wild-type isotype controls. The greatest deviation from wild-type Fc results is a reduction of $1.2 \%$ observed with huIgG4 PAA. However, differences observed between the tested variants are inconsequential because all produce average IScores of less than 5\%. IScores of less than $10 \%$ are considered to indicate very low risk of immunogenicity with a prediction that less than $10 \%$ of the U.S. population would have at least one allele predicted to bind a 9-mer located within the tested sequence. A further breakdown of the IScore data into number of predicted agretopes, as well as number of low, medium and high PIR agretopes for each sequence of interest is shown in Figure 11B. Again, individual predicted agretopes show all sequences having similar immunogenic risk profiles as their corresponding wild-type Fc sequences, where predicted agretopes would likely be tolerogenic. None of the Fc variants are predicted to generate any high PIR agretopes (i.e., over 50\% of the U.S. population having at least one MHC allele predicted to bind the 9-mer).
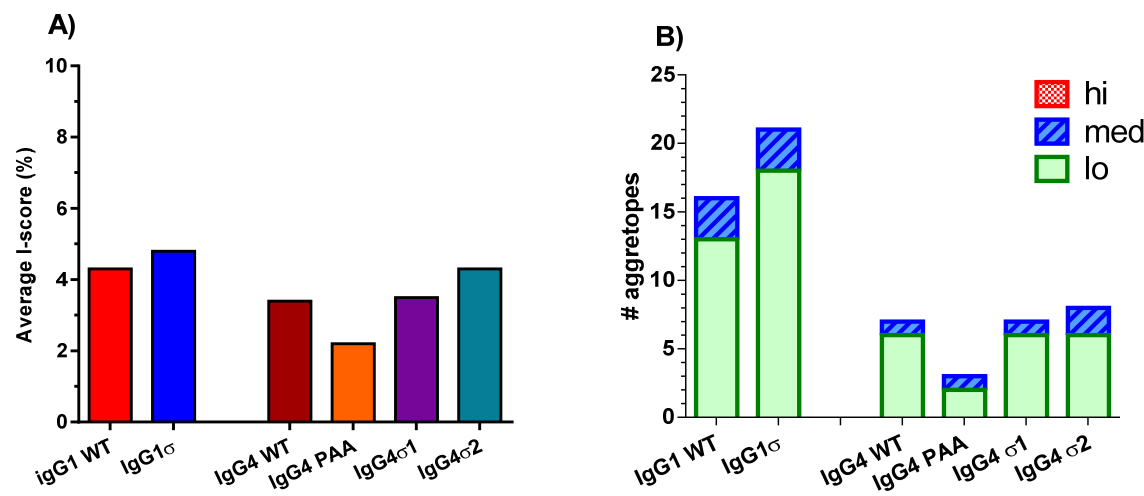

Figure 11. ImmunoFilter ${ }^{\mathrm{TM}}$ analyses of the human IgG variants. The amino acid sequences for the different variants were analyzed for predicted immunogenicity in silico using ImmunoFilter ${ }^{\mathrm{TM}}$ v2.7. (A) IScores summary which approximated the percent of US population expected to have a human leukocyte antigen (HLA) allele predicted to bind a nine-mer peptide within a sequence of interest. (B) The number of individual agretopes and their associated risk potential based on the percent of the population expected to have an allele predicted to bind each agretope (low (lo) $=10-25 \%$, medium $($ med $)=25-50 \%$, and high (hi) $=$ over $50 \%$ of the U.S. population). Resulting IScores were averaged across all loci. Higher IScores indicate a higher predicted immunogenicity risk. 


\subsection{Developability Assessment}

A panel of biophysical assays was conducted on Abs with Fc variations to assess potential problems in developability that might impact the development and commercial manufacturing of therapeutics. These studies included assessing antibody thermal stability, the stability of highly concentrated samples over time, and stability at low $\mathrm{pH}$. The results are described in the sub-sections below.

\subsubsection{Thermal Stability}

Differential Scanning Calorimetry (DSC) was used to assess the thermal stability of Ab1 Fc variants. A summary which includes the mid-point of denaturation ( $\mathrm{Tm}$ ) for the transitions is shown in Table 2. HuIgG1 (WT), huIgG1 AA and huIgG2 have similar $\operatorname{Tm} 1\left(\mathrm{C}_{\mathrm{H}} 2\right.$ domain) transitions, but huIgG1 FES, huIgG1 $\sigma$, huIgG2 $\sigma$, huIgG4 PAA, huIgG4 $\sigma 1$ and huIgG4 $\sigma 2$ show lower Tm1 transition values, suggesting reduced stability of its $\mathrm{C}_{\mathrm{H}} 2$ domain attributable to the presence of mutations (Table 1). Ab1 huIgG2 Tm1 transition is $71.6 \pm 0.1{ }^{\circ} \mathrm{C}$, while the huIgG2 $\sigma$ variant is $62.0 \pm 0.2{ }^{\circ} \mathrm{C}$ for Tm1. The Ab1 huIgG4 PAA shows a first transition at $69.5 \pm 0.1{ }^{\circ} \mathrm{C}$, while the huIgG4o1 is at $62.0 \pm 0.2{ }^{\circ} \mathrm{C}$ and the huIgG4 $\sigma 2$ is at $61.2 \pm 0.6{ }^{\circ} \mathrm{C}$, suggesting that the huIgG4 PAA is more thermally stable than its variants. The huIgG4 PAA differences are interesting given that the only sequence differences are in the first two or three residues in the lower hinge (Table 1). The Tm2 and Tm3 indicating the $\mathrm{Fab}$ and $\mathrm{C}_{\mathrm{H}} 3$ transitions are included for comparison, but generally show normal antibody transition profiles between 69 and $83^{\circ} \mathrm{C}$ [46].

Colloidal stability was evaluated over a temperature range by static light scattering (SLS) at two different wavelengths (Table 2). The scattering intensity at $266 \mathrm{~nm}$ is more sensitive to fluctuations of smaller aggregates. Measurements of scattering intensity at $473 \mathrm{~nm}$ are useful for detection of larger aggregates. The SLS data indicate the onset of aggregation (Tagg) for each antibody sample. Results comparing the antibody variants show that huIgG1 variants have higher aggregation onset temperatures around $68{ }^{\circ} \mathrm{C}$ (SLS at $266 \mathrm{~nm}$ ) compared to the huIgG2 or huIgG4 variants $\left(\right.$ Tagg $=64-65^{\circ} \mathrm{C}$ using SLS at $266 \mathrm{~nm}$ ). SLS measurements at $473 \mathrm{~nm}$ display a similar profile.

Table 2. Thermal stability of the Fc variant antibody panel.

\begin{tabular}{|c|c|c|c|c|c|c|}
\hline \multirow[t]{2}{*}{$\mathbf{A b}$} & \multirow[t]{2}{*}{ Fc Variant } & \multicolumn{3}{|c|}{$\begin{array}{l}\text { Differential Scanning } \\
\text { Calorimetry Data }\end{array}$} & \multicolumn{2}{|c|}{$\begin{array}{l}\text { Colloidal Scattering at } \\
\text { Two Wavelengths }\end{array}$} \\
\hline & & $\operatorname{Tm} 1\left({ }^{\circ} \mathrm{C}\right)$ & $\operatorname{Tm} 2\left({ }^{\circ} \mathrm{C}\right)$ & $\operatorname{Tm} 3\left({ }^{\circ} \mathrm{C}\right)$ & $\operatorname{Tagg}_{266 \mathrm{~nm}}\left({ }^{\circ} \mathrm{C}\right)$ & $\operatorname{Tagg}_{473 \mathrm{~nm}}\left({ }^{\circ} \mathrm{C}\right)$ \\
\hline $\mathrm{Ab} 1$ & IgG1 & $71.7 \pm 0.1$ & $75.2 \pm 0.1$ & $82.6 \pm 0.1$ & $67.7 \pm 0.6$ & $69.7 \pm 0.7$ \\
\hline $\mathrm{Ab} 1$ & IgG1 AA & $71.7 \pm 0.2$ & $75.0 \pm 0.1$ & $82.2 \pm 0.1$ & $68.0 \pm 0.3$ & $69.9 \pm 0.5$ \\
\hline $\mathrm{Ab} 1$ & IgG1 FES & $64.7 \pm 0.0$ & $74.0 \pm 0.1$ & $82.5 \pm 0.0$ & ND & ND \\
\hline $\mathrm{Ab} 1$ & $\operatorname{IgG1\sigma }$ & $60.8 \pm 0.1$ & $74.4 \pm 0.1$ & $82.7 \pm 0.1$ & $68.3 \pm 0.7$ & $69.8 \pm 0.6$ \\
\hline $\mathrm{Ab} 1$ & $\mathrm{IgG} 2$ & $71.6 \pm 0.1$ & $75.9 \pm 0.1$ & ND & $65.3 \pm 0.3$ & $67.6 \pm 0.3$ \\
\hline Ab1 & $\operatorname{IgG} 2 \sigma$ & $62.0 \pm 0.2$ & $74.5 \pm 0.1$ & $71.4 \pm 0.2$ & $64.0 \pm 2.1$ & $66.0 \pm 1.7$ \\
\hline $\mathrm{Ab} 1$ & IgG4 PAA & $69.5 \pm 0.1$ & $73.4 \pm 0.1$ & ND & $63.8 \pm 1.7$ & $66.0 \pm 0.6$ \\
\hline Ab1 & $\operatorname{IgG} 4 \sigma 1$ & $62.0 \pm 0.2$ & $70.8 \pm 0.1$ & $73.8 \pm 0.1$ & $64.1 \pm 1.4$ & $66.0 \pm 0.5$ \\
\hline $\mathrm{Ab} 1$ & $\operatorname{IgG} 4 \sigma 2$ & $61.2 \pm 0.6$ & $69.9 \pm 0.6$ & $73.2 \pm 0.4$ & $63.8 \pm 1.8$ & $66.0 \pm 0.5$ \\
\hline
\end{tabular}

Antibody (Ab) samples are in PBS; values are shown as \pm range. Abbreviations: ND, no data; fragment crystallizable, Fc; temperature of melting at midpoint, Tm; IgG1 AA, IgG1 L234A/L235A; IgG1 FES, IgG1 L234F/L235E/P331S; IgG4 PAA, IgG4 S228P/F234A/L235A.

\subsubsection{Stability of Concentrated Samples}

Samples were concentrated from their initial concentration of $1-2 \mathrm{mg} / \mathrm{mL}$ to $40-50 \mathrm{mg} / \mathrm{mL}$ and stored at $4{ }^{\circ} \mathrm{C}$. Table 3 summarizes the antibody concentrations and Table 4 summarizes the size exclusion chromatography (SEC) analyses at time of lot release, week 1, week 2, week 3, and week 4 post-release. All molecules show stable antibody concentrations for up to 4 weeks storage at $2-8{ }^{\circ} \mathrm{C}$ in PBS. The increasing concentration values observed for all samples with time are attributed 
to sample evaporation during storage. Aliquots at these time points were diluted and analyzed by SEC. All samples appear visibly clear and SEC analyses results indicate that all molecules at high concentrations consist of greater than $95 \%$ monodisperse monomeric antibody.

Table 3. Stability of Concentrated Proteins Stored at $4{ }^{\circ} \mathrm{C}$ (concentration of antibodies over time).

\begin{tabular}{|c|c|c|c|c|c|}
\hline Sample ID & $\begin{array}{l}\text { Release concentration } \\
\qquad(\mathrm{mg} / \mathrm{mL})\end{array}$ & $\begin{array}{l}\text { Week } 1 \\
(\mathrm{mg} / \mathrm{mL})\end{array}$ & $\begin{array}{l}\text { Week } 2 \\
(\mathrm{mg} / \mathrm{mL})\end{array}$ & $\begin{array}{l}\text { Week } 3 \\
(\mathrm{mg} / \mathrm{mL})\end{array}$ & $\begin{array}{l}\text { Week } 4 \\
(\mathrm{mg} / \mathrm{mL})\end{array}$ \\
\hline IgG1 & $53.9 \pm 0.8$ & $53.1 \pm 0.3$ & $57.2 \pm 0.7$ & $55.1 \pm 0.4$ & $55.0 \pm 0.3$ \\
\hline IgG1 FES & $45.5 \pm 0.9$ & $48.8 \pm 1.2$ & $46.4 \pm 0.7$ & $46.7 \pm 0.3$ & $46.6 \pm 1.5$ \\
\hline $\mathrm{IgG} 1 \sigma$ & $41.9 \pm 0.6$ & $41.5 \pm 0.2$ & $42.0 \pm 0.3$ & $42.5 \pm 0.9$ & $43.4 \pm 0.5$ \\
\hline $\mathrm{IgG} 2$ & $41.4 \pm 0.1$ & $40.5 \pm 0.2$ & $42.0 \pm 0.4$ & $42.9 \pm 0.2$ & $43.0 \pm 0.8$ \\
\hline $\operatorname{IgG} 2 \sigma$ & $40.8 \pm 0.5$ & $41.3 \pm 0.4$ & $40.9 \pm 0.6$ & $41.7 \pm 1.1$ & $41.8 \pm 0.6$ \\
\hline IgG4-PAA & $48.6 \pm 1.5$ & $50.6 \pm 0.6$ & $52.5 \pm 1.0$ & $53.2 \pm 0.2$ & $50.9 \pm 1.3$ \\
\hline $\operatorname{IgG} 4 \sigma 1$ & $50.4 \pm 0.4$ & $50.3 \pm 0.1$ & $50.0 \pm 0.6$ & $50.0 \pm 0.2$ & $51.4 \pm 0.8$ \\
\hline IgG4 62 & $51.7 \pm 1.1$ & $51.3 \pm 0.4$ & $48.4 \pm 2.1$ & $53.4 \pm 1.6$ & $54.8 \pm 0.7$ \\
\hline
\end{tabular}

$\mathrm{Ab}$ samples are in PBS and shown as mean \pm range. Abbreviations: IgG1 AA, IgG1 L234A/L235A; IgG1 FES, IgG1 L234F/L235E/P331S; IgG4 PAA, IgG4 S228P/F234A/L235A.

Table 4. Size exclusion chromatography (SEC) analyses with percent monomer of concentrated proteins.

\begin{tabular}{|c|c|c|c|c|}
\hline Sample Name & Release (\%) & Week 1 (\%) & Week 2 (\%) & Week 4 (\%) \\
\hline IgG1 & 100.0 & 100.0 & 99.6 & 99.4 \\
\hline IgG1 FES & 100.0 & 100.0 & 100.0 & 99.0 \\
\hline $\operatorname{IgG} 1 \sigma$ & 100.0 & 100.0 & 99.7 & 99.3 \\
\hline $\mathrm{IgG} 2$ & 98.17 & 98.0 & 97.9 & 97.7 \\
\hline $\operatorname{IgG} 2 \sigma$ & 100.0 & 100.0 & 99.2 & 100.0 \\
\hline IgG4 PAA & 100.0 & 99.6 & 99.5 & 99.5 \\
\hline $\operatorname{IgG} 4 \sigma 1$ & 98.0 & 97.9 & 97.7 & 97.5 \\
\hline $\operatorname{IgG} 4 \sigma 2$ & 97.8 & 97.9 & 97.7 & 97.4 \\
\hline
\end{tabular}

Representative data of SEC analysis. Abbreviations: IgG1 AA, IgG1 L234A/L235A; IgG1 FES, IgG1 L234F/L235E/P331S; IgG4 PAA, IgG4 S228P/F234A/L235A.

To obtain a more complete picture of the stability of the Fc variants, protein melting points and aggregation onset temperature were measured for each by a combination of intrinsic fluorescence and static light scattering. Table 5 summarizes the mid-point values for thermal transition, Tm1, and for onset of aggregation at Tagg $=266 \mathrm{~nm}$. Tm values for the concentrated antibody variants are similar between the release lot and the week 4 samples. Tagg values of the $266 \mathrm{~nm}$ values are also similar for the release lot and week 4 samples. Thus, the variants have not changed their conformational or colloidal stabilities at high concentrations.

Table 5. Tm and temperature of aggregation (Tagg) of Fc variants at high concentration $(40-50 \mathrm{mg} / \mathrm{mL})$.

\begin{tabular}{|c|c|c|c|}
\hline Antibody & Week & $\operatorname{Tm} 1\left({ }^{\circ} \mathrm{C}\right)$ & $\operatorname{Tagg}_{266 n m}\left({ }^{\circ} \mathrm{C}\right)$ \\
\hline IgG1 & $\mathrm{R}$ & $69.3 \pm 1.4$ & $68.0 \pm 0.1$ \\
\hline IgG1 & Week 0 & $68.2 \pm 0.5$ & $67.4 \pm 0.6$ \\
\hline IgG1 & Week 4 & $68.3 \pm 0.3$ & $67.6 \pm 0.8$ \\
\hline $\operatorname{IgG} 1 \sigma$ & R & $61.5 \pm 1.0$ & $68.9 \pm 0.3$ \\
\hline $\operatorname{IgG} 1 \sigma$ & Week 0 & $60.6 \pm 0.2$ & $67.8 \pm 0.3$ \\
\hline 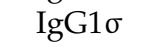 & Week 4 & $60.8 \pm 0.1$ & $67.9 \pm 0.7$ \\
\hline IgG1 AA & R & $69.3 \pm 0.5$ & $68.3 \pm 0.3$ \\
\hline IgG1 AA & Week 0 & $68.2 \pm 0.0$ & $67.7 \pm 0.2$ \\
\hline IgG1 AA & Week 4 & $68.4 \pm 0.1$ & $68.1 \pm 0.2$ \\
\hline IgG1 FES & $\mathrm{R}$ & $65.9 \pm 0.8$ & $67.7 \pm 0.1$ \\
\hline IgG1 FES & Week 0 & $64.9 \pm 0.6$ & $66.9 \pm 0.3$ \\
\hline IgG1 FES & Week 4 & $65.1 \pm 0.1$ & $67.5 \pm 0.2$ \\
\hline
\end{tabular}


Table 5. Cont.

\begin{tabular}{|c|c|c|c|}
\hline Antibody & Week & $\operatorname{Tm} 1\left({ }^{\circ} \mathrm{C}\right)$ & $\operatorname{Tagg}_{266 n m}\left({ }^{\circ} \mathrm{C}\right)$ \\
\hline IgG2 & $\mathrm{R}$ & $67.5 \pm 1.8$ & $65.1 \pm 0.8$ \\
\hline IgG2 & Week 0 & $66.5 \pm 0.4$ & $65.6 \pm 0.1$ \\
\hline $\mathrm{IgG2}$ & Week 4 & $66.7 \pm 0.4$ & $65.2 \pm 1$ \\
\hline $\operatorname{IgG} 2 \sigma$ & $\mathrm{R}$ & $61.7 \pm 0.8$ & $61.9 \pm 2.4$ \\
\hline $\operatorname{IgG} 2 \sigma$ & Week 0 & $62.6 \pm 0.2$ & $66.2 \pm 0.1$ \\
\hline $\operatorname{IgG} 2 \sigma$ & Week 4 & $62.7 \pm 0.2$ & $66.8 \pm 0.4$ \\
\hline IgG4 PAA & $\mathrm{R}$ & $66.4 \pm 1.9$ & $62.1 \pm 0.5$ \\
\hline IgG4 PAA & Week 0 & $66.2 \pm 0.6$ & $65.5 \pm 1.3$ \\
\hline IgG4 PAA & Week 4 & $66.3 \pm 0.2$ & $65.9 \pm 0.1$ \\
\hline $\operatorname{IgG4\sigma 1}$ & $\mathrm{R}$ & $61.5 \pm 0.1$ & $62.7 \pm 0.9$ \\
\hline IgG4 61 & Week 0 & $62.0 \pm 0.2$ & $65.5 \pm 0.2$ \\
\hline $\operatorname{IgG} 4 \sigma 1$ & Week 4 & $62.0 \pm 0.4$ & $66.1 \pm 0.0$ \\
\hline $\operatorname{IgG} 4 \sigma 2$ & $\mathrm{R}$ & $61.6 \pm 0.7$ & $62.0 \pm 1.5$ \\
\hline $\operatorname{IgG} 4 \sigma 2$ & Week 0 & $61.8 \pm 0.1$ & $65.6 \pm 0.1$ \\
\hline $\operatorname{IgG} 4 \sigma 2$ & Week 4 & $62.1 \pm 0.2$ & $65.9 \pm 0.1$ \\
\hline
\end{tabular}

$\mathrm{Tm} 1$ and Tagg $266 \mathrm{~nm}$ values = mean \pm range; $\mathrm{Ab}$ samples are in PBS. $\mathrm{R}$ is the Release material; Week 0 is data after concentration of material; Week 4 is data after week 4 of incubation.

\subsubsection{Stability of Low $\mathrm{pH}$ Treated Antibody Fc Variants}

To assess whether the Fc variants are stable after low $\mathrm{pH}$ treatment for viral load reduction in manufacturing, antibody samples were treated at $\mathrm{pH} 3.5$ for $6 \mathrm{~h}$ and dialyzed back to $\mathrm{pH} 7.4$ in PBS. Dynamic light scattering analyses were performed to quantitate presence of soluble aggregates and sub-visible particles. Table 6 shows the average hydrodynamic radius $\left(R_{h}\right)$, percent polydispersity (\% Pd) values, and percent mass comparison between the release lot and the low $\mathrm{pH}$ treated samples. All samples yielded a peak with an average radius of 5-7 nm, average $\%$ Pd of less than $15 \%$, and an average $\%$ Mass of greater than $99 \%$. These features are indicative of a mono-dispersed species for the antibody variants.

Table 6. Dynamic light scattering data after low $\mathrm{pH}$ treatment.

\begin{tabular}{|c|c|c|c|c|c|c|}
\hline \multirow{2}{*}{ Ab1 } & $\operatorname{Avg} R_{h}$ & Avg \%Pd & Avg \%Mass & $\operatorname{Avg} R_{h}$ & Avg \%Pd & Avg \%Mass \\
\hline & \multicolumn{3}{|c|}{ Release Material } & \multicolumn{3}{|c|}{ Low pH Material } \\
\hline $\operatorname{IgG1}$ & $5.4 \pm 0.1$ & $10.3 \pm 2.1$ & $100.0 \pm 0.0$ & $5.1 \pm 0.2$ & $12.2 \pm 1.7$ & $100.0 \pm 0.0$ \\
\hline $\operatorname{IgG} 1 \sigma$ & $5.4 \pm 0.0$ & $9.6 \pm 0.3$ & $100.0 \pm 0.0$ & $5.0 \pm 0.2$ & $13.2 \pm 0.8$ & $100.0 \pm 0.0$ \\
\hline IgG1 AA & $5.8 \pm 0.3$ & $16.7 \pm 10.1$ & $100.0 \pm 0.1$ & $5.5 \pm 0.2$ & $12.2 \pm 7.1$ & $100.0 \pm 0.0$ \\
\hline IgG1 FES & $5.5 \pm 0.0$ & $7.7 \pm 1.6$ & $100 \pm 0.0$ & $5.2 \pm 0.1$ & $11.9 \pm 1.3$ & $99.7 \pm 0.6$ \\
\hline $\operatorname{IgG} 2$ & $5.8 \pm 0.1$ & $18.2 \pm 5.2$ & $99.6 \pm 0.1$ & $5.0 \pm 0.1$ & $13.2 \pm 0.6$ & $100.0 \pm 0.0$ \\
\hline $\operatorname{IgG} 2 \sigma$ & $5.4 \pm 0.0$ & $13.0 \pm 3.6$ & $100.0 \pm 0.0$ & $5.1 \pm 0.2$ & $12.5 \pm 1.5$ & $99.6 \pm 0.8$ \\
\hline IgG4-PAA & $5.3 \pm 0.1$ & $9.9 \pm 0.6$ & $100.0 \pm 0.0$ & $5.3 \pm 0.0$ & $10.4 \pm 0.8$ & $100.0 \pm 0.0$ \\
\hline $\operatorname{IgG4\sigma 1}$ & $5.4 \pm 0.1$ & $9.3 \pm 0.5$ & $100.0 \pm 0.0$ & $6.4 \pm 0.2$ & $15.5 \pm 1.6$ & $100.0 \pm 0.0$ \\
\hline $\operatorname{IgG} 4 \sigma 2$ & $5.4 \pm 0.0$ & $8.9 \pm 0.4$ & $100.0 \pm 0.0$ & $6.6 \pm 0.1$ & $14.8 \pm 1.3$ & $100.0 \pm 0.0$ \\
\hline
\end{tabular}

Samples were tested at $1 \mathrm{mg} / \mathrm{mL}$ in triplicate and shown as mean \pm standard deviation (STD). Avg_average; Percent polydispersity $(\% \mathrm{Pd})$; hydrodynamic radius $\left(\mathrm{R}_{\mathrm{h}}\right)$.

\subsection{Fc Crystal Structures}

To assess the impact of the silencing mutations on the structure of the $\mathrm{Fc}_{\mathrm{c}}$, crystal structures of the

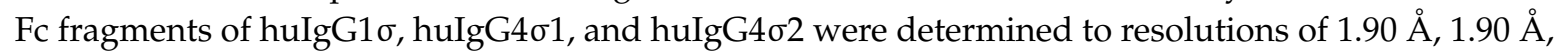
and $1.85 \AA$, respectively. Data collection and refinement statistics are summarized in Table 7. Crystals of all three $\mathrm{Fc}$ constructs belonged to space group $\mathrm{P} 2{ }_{1} 2_{1} 2_{1}$, and had similar unit cell parameters. This isomorphism reflects a similarity in Fc packing within the crystal lattice where one intact Fc dimer is present in the asymmetric unit. In this crystal form, the $A$ chain $\mathrm{C}_{\mathrm{H}} 2$ domain is less ordered as evidenced by the reduced quality of the electron density map and elevated temperature factors of the 
atoms. The reason for this is that the $\mathrm{C}_{\mathrm{H}} 2$ domains of the $\mathrm{A}$ and $\mathrm{B}$ chains have a difference in the crystal contacts. For the three $F_{C}$ structures reported here and excluding the glycan contributions, the $B$ chain has an average of $2082 \pm 186 \AA^{2}$ of buried surface area through interaction with symmetry related Fc molecules compared with only $1477 \pm 181 \AA^{2}$ of buried surface area for chain A. Consequently, for the three structures, the average B-factor calculated over residues 238-339 and glycan residues for chains B and A was $37.6 \pm 4.5 \AA^{2}$ and $54.1 \pm 1.8 \AA^{2}$, respectively.

The huIgG1 $\sigma$ Fc structure includes residues G236-S444 and A235-S444 for chains A and B, respectively, which are only those observed in the electron density map (Figure S1). The structure reveals conformational differences in ordered residues N-terminal to V240 and within the BC loop (residues S267 to V273) relative to wild-type huIgG1 Fc (e.g., PDB 3AVE [40]) and receptor-bound Fc structures (e.g., PDB 3SGK [47]). These regions can directly influence interactions with Fc $\gamma$ Rs. The lower hinge regions of wild-type huIgG1 structures, including those in complex with Fc $\gamma$ Rs, show extended conformations while that of huIgG1 $\sigma$ has a kinked conformation at S239 (Figures 12 and S1). The backbone psi angle value for S239 averaged over both chains in the huIgG1 $\sigma$ Fc structure is $10^{\circ}$ compared to an average value of $145^{\circ}$ for wild-type huIgG1 in structure 3AVE [40]. It should be noted that the altered lower hinge conformation is not a requirement of crystal packing (Figure S2). Interestingly, the kinked conformation is observed in structures of two other engineered Fcs in complex with Fc $\gamma$ RIlb, a P238D mutant (PDB 3WJJ [48]) and an Fc having the P238D mutation in addition to six other mutations (PDB 3WJL [48]) (Figure 12).

Table 7. X-ray crystallographic data and refinement statistics.

\begin{tabular}{|c|c|c|c|}
\hline & $\operatorname{IgG1\sigma } \mathrm{Fc}$ & IgG4 $\sigma 1 \mathrm{Fc}$ & $\operatorname{IgG} 4 \sigma 2 \mathrm{Fc}$ \\
\hline \multicolumn{4}{|l|}{ Crystal Data } \\
\hline Space group & $\mathrm{P} 2{ }_{1} 2_{1} 2_{1}$ & $\mathrm{P} 2{ }_{1} 2_{1} 2_{1}$ & $\mathrm{P} 2{ }_{1}{ }_{1} 2_{1}$ \\
\hline \multicolumn{4}{|l|}{ Unit cell parameters } \\
\hline$a, b, c(\AA)$ & $73.36,79.17,101.44$ & $74.74,78.39,97.39$ & $74.52,78.47,97.51$ \\
\hline$\alpha, \beta, \gamma\left(^{\circ}\right)$ & $90.0,90.0,90.0$ & $90.0,90.0,90.0$ & $90.0,90.0,90.0$ \\
\hline Resolution $(\AA)$ & $50.00-1.90(1.95-1.90)^{\mathrm{a}}$ & $50.00-1.90(1.95-1.90)$ & $50.0-1.85$ (1.90-1.85) \\
\hline Measured reflections & $256,516(19,366)$ & $248,644(18,842)$ & $363,451(27,057)$ \\
\hline Unique reflections & $47,175(3427)$ & $45,491(3348)$ & $49,481(3648)$ \\
\hline Completeness (\%) & 99.7 (99.7) & $99.4(99.9)$ & $99.9(100.0)$ \\
\hline Redundancy & $5.4(5.7)$ & $5.5(5.6)$ & $7.3(7.4)$ \\
\hline $\mathrm{R}_{\text {merge }} \mathrm{b}$ & $0.041(0.539)$ & $0.045(0.588)$ & $0.056(0.670)$ \\
\hline$<\mathrm{I} / \sigma\rangle^{\mathrm{c}}$ & $21.3(2.9)$ & $18.6(2.8)$ & $19.8(3.0)$ \\
\hline \multicolumn{4}{|l|}{ Refinement Statistics } \\
\hline Resolution $(\AA)$ & $33.28-1.90$ & $32.70-1.90$ & $47.26-1.85$ \\
\hline Number of reflections & 47,088 & 45,473 & 49,469 \\
\hline $\mathrm{R}_{\text {work }}(\%)^{\mathrm{d}}$ & 19.2 & 18.2 & 18.1 \\
\hline $\mathrm{R}_{\text {free }}(\%)^{\mathrm{d}}$ & 22.9 & 22.5 & 21.5 \\
\hline Number atoms & 3772 & 3771 & 3897 \\
\hline Protein & 3292 & 3320 & 3404 \\
\hline Carbohydrate & 220 & 220 & 210 \\
\hline Solvent & 260 & 231 & 283 \\
\hline Mean B-factor $\left(\AA^{2}\right)$ & 41.9 & 45.9 & 40.0 \\
\hline Protein & 40.4 & 43.7 & 37.9 \\
\hline Carbohydrate & 58.5 & 75.7 & 66.2 \\
\hline Solvent & 46.4 & 50.0 & 45.9 \\
\hline \multicolumn{4}{|l|}{$\mathrm{RMSD}^{\mathrm{e}}$} \\
\hline Bond lengths $(\AA)$ & 0.009 & 0.012 & 0.018 \\
\hline
\end{tabular}


Table 7. Cont.

\begin{tabular}{|c|c|c|c|}
\hline & $\operatorname{IgG} 1 \sigma \mathrm{Fc}$ & IgG4 $\sigma 1 \mathrm{Fc}$ & $\operatorname{IgG} 4 \sigma 2 \mathrm{Fc}$ \\
\hline Bond angles $\left({ }^{\circ}\right)$ & 1.213 & 1.438 & 1.699 \\
\hline \multicolumn{4}{|l|}{ Ramachandran } \\
\hline Favored (\%) & 98.1 & 98.8 & 98.1 \\
\hline Allowed (\%) & 1.9 & 1.2 & 1.9 \\
\hline Outliers (\%) & 0.0 & 0.0 & 0.0 \\
\hline
\end{tabular}

a Values for high resolution shell are shown in parentheses. ${ }^{b} R_{\text {merge }}=\Sigma_{\text {hkl }} \Sigma_{\mathrm{i}}\left(\left|<\mathrm{I}_{\text {hkl }}>-\mathrm{I}_{\mathrm{hkl}, \mathrm{i}}\right|\right) / \Sigma_{\mathrm{hkl}} \Sigma_{\mathrm{i}} \mathrm{I}_{\mathrm{hkl}, \mathrm{I}}$, where $\mathrm{hkl}$ enumerates the unique reflections and $\mathrm{i}$ their symmetry-equivalent or multiply-measured contributors. I is the intensity for a given measurement. ${ }^{c}\langle\mathrm{I} / \sigma\rangle$ is the average $\mathrm{x}$-ray reflection intensity (I) measurement divided by the standard deviation of that measurement $(\sigma)$ for the whole X-ray data set. ${ }^{\mathrm{d}} \mathrm{R}=\left(\Sigma_{\mathrm{hkl}}|| \mathrm{F}_{\mathrm{obs}}(\mathrm{hkl}) \mid-\right.$ $\left.\left|F_{\text {calc }}(\mathrm{hkl})\right| \mathrm{I}\right) /\left(\Sigma_{\text {hkl }}\left|\mathrm{F}_{\mathrm{obs}}(\mathrm{hkl})\right|\right)$, where $\mathrm{F}_{\mathrm{obs}}(\mathrm{hkl})$ and $\mathrm{F}_{\text {calc }}(\mathrm{hkl})$ are the observed and calculated structure factors. $R_{\text {work }}$ includes structure factors for the entire data set minus those data sequestered for computing $R_{\text {free }} . R_{\text {free }}$ includes only the latter randomly chosen subset of the data. ${ }^{e}$ RMSD (Root Mean Square Deviation) in the table describes how well the atomic bond distances and angles compare to idealized values determined from a set of reference structures.

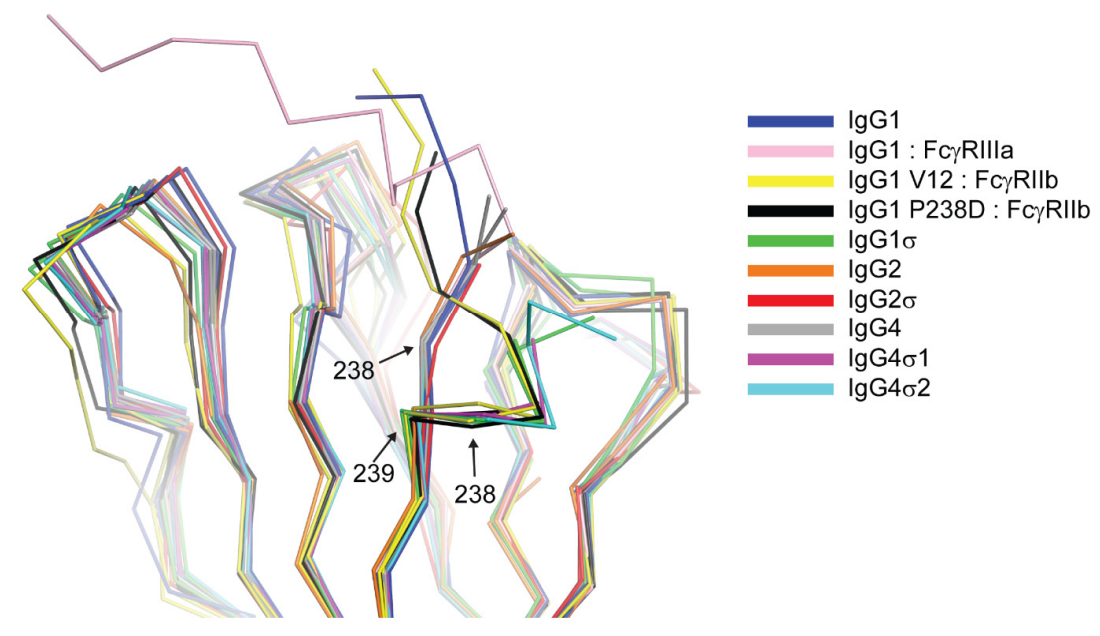

Figure 12. Structural consequence of mutation at position 238 reveals an altered conformation of the lower hinge. Backbone alignment of $\mathrm{Fc}_{\mathrm{C}} \mathrm{C}_{\mathrm{H}} 2$ domains of huIgG1 (Protein Data Bank (PDB) 3AVE [40]), huIgG1 in complex with Fc $\gamma$ RIIIa (chain B, PDB 3SGJ [47]), huIgG1 V12 variant in complex

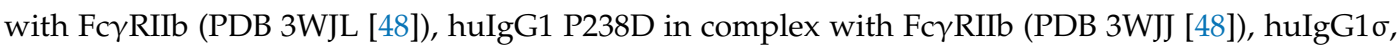

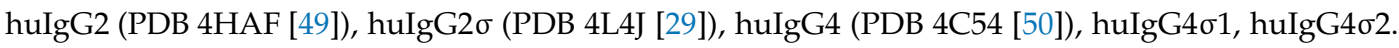
The $\mathrm{C} \alpha$ positions of residues 238 and 239 are labeled.

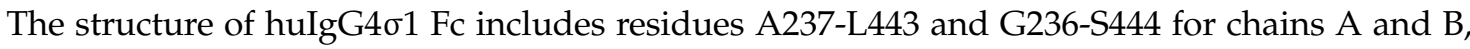

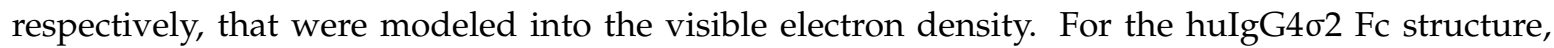
residues S238-L443 and E233-S444 were modeled for the respective chains (Figure S1). The lower

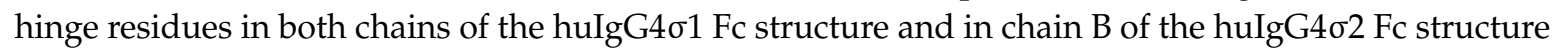
adopt a kinked conformation like that described above for huIgG1 $\sigma$ (Figures 12 and S1). In contrast, the same residues in chain A of the huIgG4 $\sigma 2$ structure adopt a wild-type-like extended conformation (Figure 12). All these Fcs having a kinked lower hinge also contain the mutation of P238, however, the structure of huIgG2 $\sigma$ (PDB 4L4J [29]) and chain A of huIgG4\%2 indicate that this mutation does not restrict the conformation to the kinked form.

Previous crystal structures of huIgG1, huIgG2 and huIgG4 have shown two distinct conformations for the BC loop (residues 267 to 273) and the FG loop (residues 322 to 332) that seem to correlate with the ability to bind to Fc $\gamma$ Rs. Denoting the two conformations as 'flipped-in' and 'flipped-out', both loops are in the flipped-in conformation in structures of wild-type huIgG1 FC (PDB 3AVE [40]) and huIgG2 Fc (PDB 4HAF [49]), whereas they adopt the flipped-out conformation

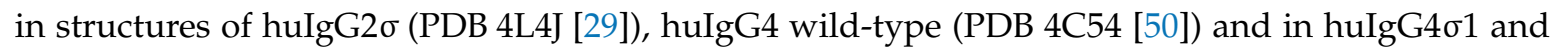




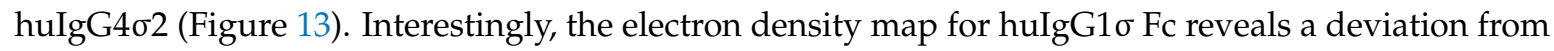
this pattern such that the primary conformation of the BC loop is the flipped-out conformation while that of the FG loop is the wild-type flipped-in conformation. In chain A, for which the density is poorer, these are the only conformations evident. In chain B, density is also present for the flipped-in conformation of the BC loop, and this conformation refined to an occupancy of $40 \%$. Density for the FG loop in chain B suggests an increased mobility for this loop, but was not well enough defined to model a second conformation. Whereas crystal packing precludes a flipped-out FG conformation for one of the two Fc chains in the huIgG1 $\sigma$ structure, a flipped-out conformation could be tolerated for the second (Figure S3). In the wild-type huIgG1 Fc structure (PDB 3AVE [40]), residue P271 in a flipped-out conformation of the BC loop would clash with the flipped-in FG loop. However, this clash is avoided in huIgG1 $\sigma$ by a deflection of the FG loop as a rigid body (Figure 13). In addition to the deviation in conformations of the BC and FG loops for the huIgG1 $\sigma$ Fc, the structural studies suggest an increased mobility for these two loops that may play a direct role in how this Fc interacts with the Fc $\gamma$ Rs.

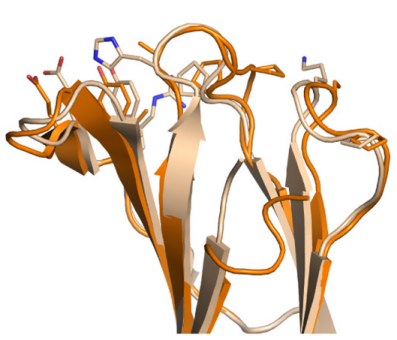

A

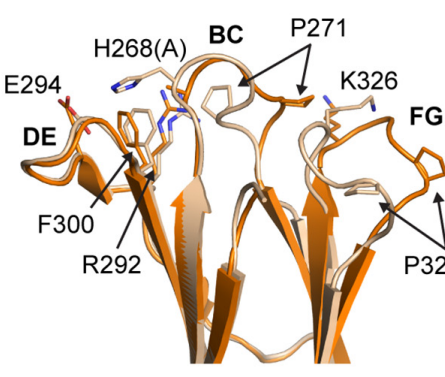

B

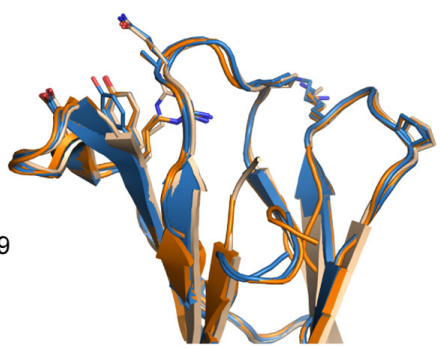

C

Figure 13. Conformational differences in BC and FG loops in WT and $\sigma$ variants of huIgG. (A) Overlay of $\mathrm{CH} 2$ domains (cartoon) from huIgG1 (wheat, PDB 3AVE chain A [40]) and huIgG1 $\sigma$ (orange, chain B); (B) huIgG2 (wheat, PDB 4HAF chain A [49]) and huIgG2 $\sigma$ (orange, PDB 4L4J chain A [29]); (C) huIgG4 (wheat, PDB 4C54 chain A [50]), huIgG4 $\sigma 1$ (blue, chains A and B), and huIgG4 $\sigma 2$ (orange, chains A and B). BC and FG loops are in the flipped-in conformation in huIgG1 (middle, wheat) and flipped-out conformation in huIgG2 $\sigma$ (middle, orange). Residues at positions 268, 271, 292, 294, 300, 326, and 329 are shown as sticks and are labeled in the middle panel with huIgG2 sequence (mutation at position 268 in huIgG2 $\sigma$ given in parentheses). N-terminal residues 234-236 are omitted from the cartoon of huIgG1 for clarity, and the alternate conformations modeled for the BC loop of huIgG1 $\sigma$ are shown.

\subsection{Molecular Dynamics Simulations of the Fc FG and BC Loops}

To further investigate the dynamic stability of the loops in wild-type huIgG1 and huIgG1 $\sigma$ that could potentially influence Fc $\gamma \mathrm{R}$ binding, explicit solvent molecular dynamics simulations were

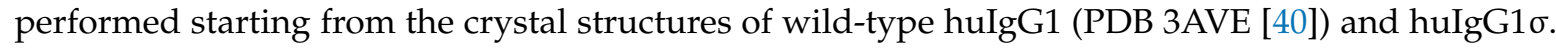
Both simulations were initiated from structures in which the FG loop was in the flipped-in conformation. For the wild-type simulation, the FG loop remained close (within $2 \AA \mathrm{C}_{\alpha} \mathrm{RMSD}$ ) to the flipped-in conformation for $57.1 \%$ of the simulation as compared to $44.4 \%$ in the case of huIgG1 $\sigma$ where the loop was found to be substantially more flexible (Figures 14 and 15). Notably, the flipped-out conformational state of the FG loop was not found to have significant population in either simulation. Figure S4 shows the spatial distribution of P329 in the FG loop, a key residue for binding to various Fc $\gamma$ Rs (e.g., [29,51]). The distribution of P329 is more tightly clustered in wild-type than in huIgG1 $\sigma$ suggesting that the FG loop in wild-type is preconfigured for receptor binding. 
A

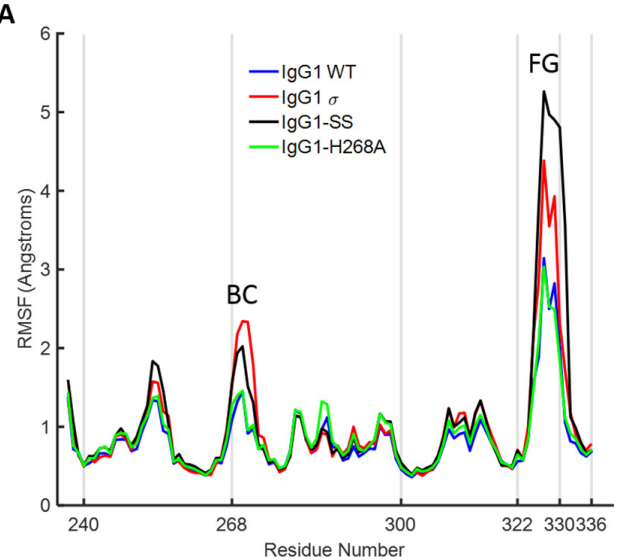

B

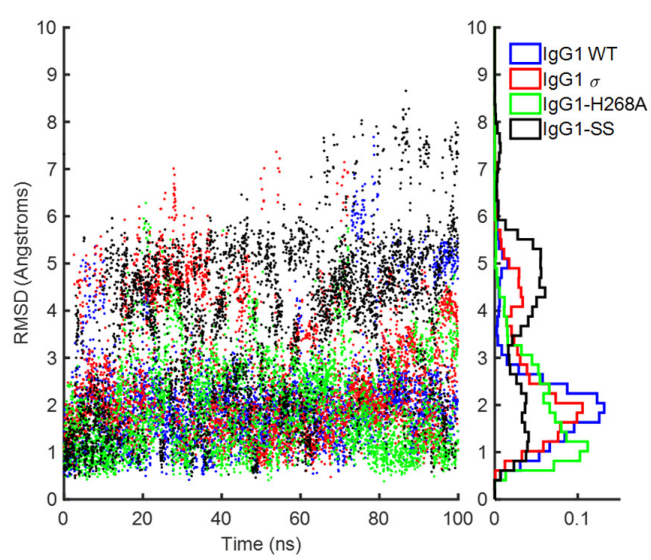

Figure 14. Molecular dynamics simulation of huIgG1 wild-type and mutants. (A) Root mean squared fluctuations (RMSF) of $\mathrm{C} \alpha$ atoms of chain $\mathrm{B}$ of $\mathrm{C}_{\mathrm{H}} 2$ domain. The trajectories are aligned on the $\mathrm{C} \alpha$ atoms with respect to the non-BC and non-FG loop residues of chain $\mathrm{B}$ of $\mathrm{C}_{\mathrm{H}} 2$ domain of the corresponding crystal structures. The peaks corresponding to the $\mathrm{BC}$ and FG loop are marked. The two loops are more flexible in huIgG1 $\sigma$ (red) as compared to wild-type (blue). The fluctuations in huIgG1-H268A (green, containing only the BC loop mutation) are closer to wild-type while those in huIgG1-SS (A330S P331S) (black, contains only the FG loop mutations) are closer to the silent variant. (B) Root mean squared deviation (RMSD) of the C $\alpha$ atoms of the FG loop with respect to the flipped-in conformation. RMSD values are shown for all frames of the 100-ns trajectory. The right panel shows a normalized histogram of the RMSD values.

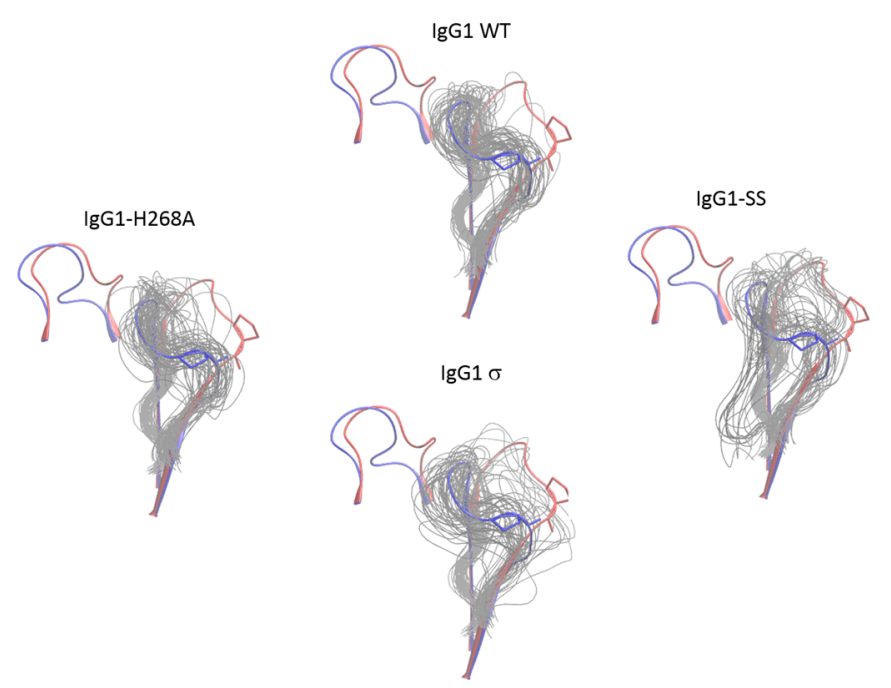

Figure 15. Conformational distribution of the FG loop of chain $B$ of $C_{H} 2$ domain from molecular dynamics simulations of huIgG1 wild-type and mutants. Each panel shows the flipped-in (blue cartoon) and flipped-out (red cartoon) conformations of the two loops. The flipped-in conformation is from the huIgG1 WT (PDB 3AVE [40]) while the flipped-out conformation is from huIgG4 WT (PDB 4C54 [50]). All simulations were started from the flipped-in conformation of the FG loop. The panels show fifty conformations (gray) sampled at an interval of $2 \mathrm{~ns}$ after aligning the molecular dynamics (MD) trajectory on the $\mathrm{C} \alpha$ atoms of the non-BC and non-FG residues of the $\mathrm{C}_{\mathrm{H}} 2$ domain of chain $\mathrm{B}$ in the corresponding crystal structure. Figure S4 shows the conformation of P329 in the above loop conformations. The FG loop of huIgG1 $\sigma$ and huIgG1-SS is significantly more flexible than that of huIgG1 WT and huIgG1-H268A. 
In addition to the FG loop, the simulations show that the BC loop is also more flexible in huIgG1 $\sigma$ than in the wild-type huIgG1 (Figures 14 and 16). In the wild-type simulation, the BC loop stays close to the initial flipped-in conformation throughout the simulation, but occupied both flipped-in and flipped-out states in the huIgG1 $\sigma$ simulation (Figure 16). This is clearly illustrated by the spatial distribution of residue P271 in the BC loop which shows a single cluster for wild-type but two distinct clusters for huIgG1 $\sigma$ (Figure S5) corresponding to the two conformational states. Interestingly, although the huIgG1 $\sigma$ simulation was initiated from the flipped-out conformation of the BC loop, the flipped-in conformation turns out to be more populated. The simulations may not be long enough to converge the populations of the two states, but strongly suggest that the BC loop of silent huIgG1 $\sigma$ is more flexible than that of the wild-type.

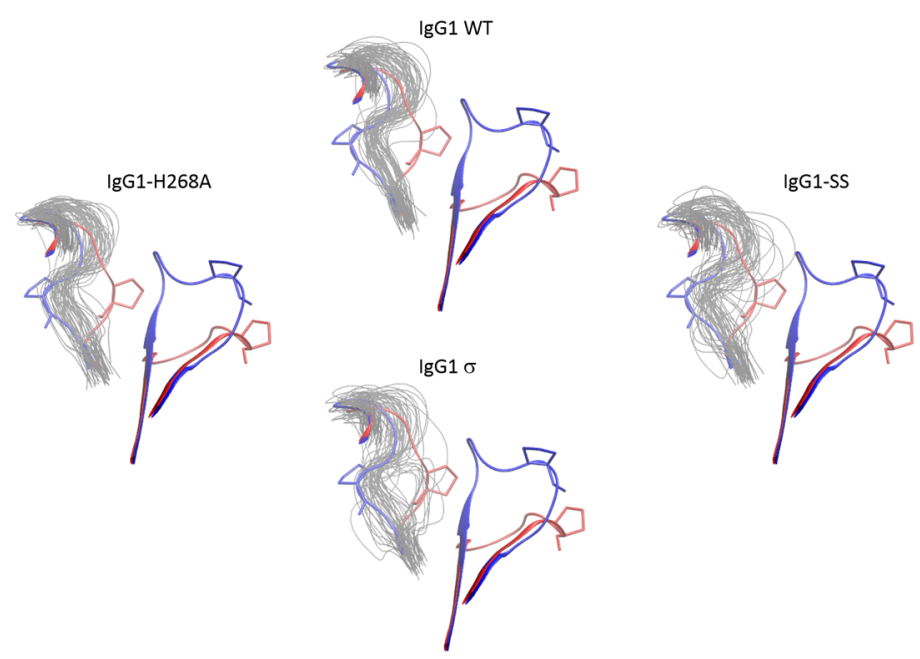

Figure 16. Conformational distribution of the $\mathrm{BC}$ loop of chain $\mathrm{B}$ of $\mathrm{C}_{\mathrm{H}} 2$ domain from molecular dynamics simulations of huIgG1 wild-type and mutants. Each panel shows the flipped-in (blue cartoon) and flipped-out (red cartoon) conformations of the two loops. The flipped-in conformation is from the huIgG1 WT (PDB 3AVE [40]) while the flipped-out conformation is from huIgG4 WT (PDB 4C54 [50]). The huIgG1 $\sigma$ was started with the BC loop in the flipped-out conformation while the other simulations started from the flipped-in conformation. The panels show fifty conformations (gray) sampled at an interval of $2 \mathrm{~ns}$ after aligning the MD trajectory on the $\mathrm{C} \alpha$ atoms of the non-BC and non-FG residues of the $\mathrm{C}_{\mathrm{H}} 2$ domain of chain $\mathrm{B}$ in the corresponding crystal structure. Figure S5 shows the conformation of P271 in the above loop conformations. In the wild-type and huIgG1-H268A simulations, the BC loop remained close to the initial flipped-in conformation of the loop. The huIgG1 $\sigma$ showed a broader distribution around the flipped-in state while huIgG1 $\sigma$ samples both flipped-in and flipped-out states though the flipped-in state was dominant.

HuIgG1 and huIgG1 $\sigma$ differ at position 268 (histidine in huIgG1, alanine in huIgG1 $\sigma$ ) in the

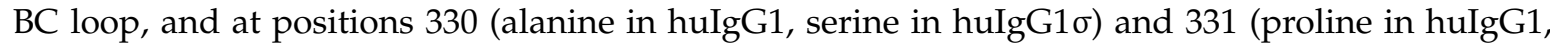
serine in huIgG1 $\sigma$ ) in the FG loop. To investigate the impact of these mutations on the flexibility of the two loops, two additional simulations were performed after modelling the mutations in the huIgG1 wild-type crystal structure. One simulation (referred to as huIgG1-H268A) contained only the BC loop mutation, and the other (referred to as huIgG1-SS) contained only the two FG loop mutations. The flexibility of both loops in the huIgG1-H268A simulation was nearly identical to that in the wild-type simulation while the flexibility in huIgG1-SS simulation was closer to that in the huIgG1 $\sigma$ simulation (Figures 14, 15, S5 and S6). The mutant simulations suggest that the A330S P331S mutations in the FG loop are primarily responsible for the increased flexibility of the two loops in huIgG1 $\sigma$; the H268A mutation in the BC loop has minimal impact. 


\section{Discussion}

Many therapeutic antibodies and Fc fusion proteins employ Fc activity as part of their mechanisms of action. Fc engagement with Fc $\gamma \mathrm{R}$ can activate myeloid cell and NK cell activity as well as the generation of reactive species that induce apoptosis and release of inflammatory cytokines which are important for eliminating unwanted target cells (i.e., tumor cells) [52-55]. However, antibody targeting to cell surface receptors can pose potential safety risks since Fc activity could elicit ADCC, ADCP, CDC, and/or apoptosis which can cause tissue damage, depletion of target cells, and infusion reactions. Although numerous antibody engineering efforts to silence the Fc activity of huIgG1 and huIgG2 have been reported $[3,16,24,25,33,34,56]$, we describe alternative novel mutations in huIgG1 $\sigma$, huIgG4 $\sigma 1$,

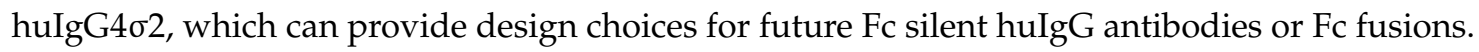

Several antibody panels (Ab1, Ab2, Ab3, Ab4, Ab5) with Fc silent mutations were constructed,

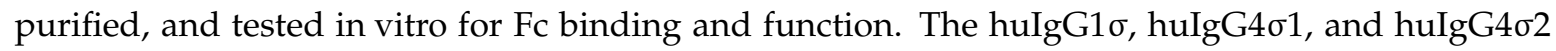
antibodies tested as immune complexes had minimal binding to Fc $\gamma$ RI, Fc $\gamma$ RIIa, Fc $\gamma$ RIIb, and Fc $\gamma$ RIIIa, compared to huIgG1 WT using concentration ranges that could be found in clinical dosing. Since the TNF $\alpha$ on target cells and Fc $\gamma$ RIII on effector cells are both multivalent, the engagement of IgG1 molecules to both cells would involve avidity. Thus, ADCC activity and the induction of immune effector function which depend on avidity and could occur at lower concentrations compared with monovalent antigen (i.e., in plate assays) [57]. Therefore, the aforementioned cell based assays provide a more sensitive measure of the degree of silencing effector function and provide a meaningful

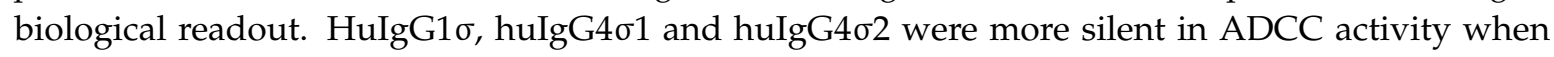
compared to huIgG1 AA, IgG1 FES, and IgG4 PAA. HuIgG4 WT was not included in the comparisons because such molecules can exchange to half-molecules in a dynamic process (Fab-arm exchange) [35]. Instead, subsequent studies were compared with HuIgG4 PAA, which has a stabilized hinge, reduced effector function, and has been used in therapeutic antibodies [25].

In vivo studies emphasize again the lack of immune functionality with the huIgG sigma variants. Results using Fc $\gamma$ R-hu mice demonstrated significantly lower levels of $\mathrm{T}$ cell dependent activation (CD69 and CD25 upregulation) with the sigma variants compared to huIgG1 AA, IgG1 FES, and huIgG4 PAA. In vivo half-life in a transgenic mouse model of human FcRn and in cynomolgus monkeys indicated that the silent mutations did not alter PK properties compared to normal huIgG. In addition, potential immunogenicity, evaluated in silico (for protein sequence "hot spots" that favor immune response initiation) predicts minimal immunogenic risk for these silent Fc variants. Although ex vivo immune responses measured by T cell proliferation and IL-2 secretion, were not tested here, the huIgG2 $\sigma$ (reported previously) shows relatively low risk of clinical immunogenicity as determined by comparing the frequency and magnitude of ex vivo T cell responses [29]. The IgG1 and IgG4 sigma variants with very similar mutations and low predicted immunogenic risk are likely to have similar non-immunogenic profiles.

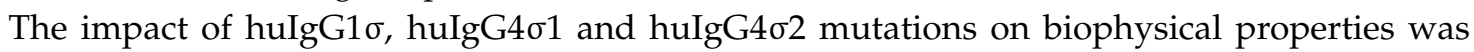
assessed for their effect on manufacturing. Thermal stress for all the sigma variants compared to their wild-type versions, suggests lower thermal stabilities in the $\mathrm{C}_{\mathrm{H}} 2$ and hinge regions. However, there is little evidence that reduced thermal stability of these magnitudes translates into developability issues or in vivo stability issues. All Fc variants are stable for 4 weeks when concentrated (to $40-50 \mathrm{mg} / \mathrm{ML}$ ), or subjected to low $\mathrm{pH}$ stress. Also, there are no additional post-translational modifications or significant changes in solution particle size associated with these $\mathrm{Fc}_{\mathrm{C}}$ mutations.

In the analysis of Fc:Fc $\gamma R$ structures, the packing of P329 in the $\mathrm{C}_{\mathrm{H}} 2$ domain FG loop between two tryptophan side chains in the Fc receptor is a conserved feature of huIgG Fc interaction with Fc $\gamma R I$ (e.g., 4W4O [51]), Fc $\gamma$ RIIb (e.g., 3WJJ [48]), and Fc $\gamma$ RIIIa (e.g., 3SGJ [47]). The receptor bound conformation of the FG loop is like its conformation in apo-structures of huIgG1 Fc and huIgG2 Fc suggesting that in these subtypes, the FG loop is preconfigured for receptor engagement (Figure S6). The structure of huIgG2 $\sigma$, an engineered silent variant of huIgG2, first revealed a unique flipped conformation for the FG loop that was proposed to be responsible in part for the diminished receptor 
interaction of this variant. The same structure also revealed a unique, flipped conformation of the $\mathrm{BC}$ loop relative to wild-type structures of huIgG1 Fc and huIgG2 Fc. Herein, we denote the conformations of the BC and FG loops as observed in a prototypical structure of huIgG1 wild-type Fc (e.g., PDB 3AVE [40]) as flipped-in and the altered conformations of the same loops observed in the crystal structure of huIgG2 $\sigma$ (PDB 4L4J [29]) as flipped-out (Figure 13).

It has been proposed that, in the case of huIgG2 $\sigma$, the H268A mutation in the BC loop abolished an electrostatic interaction with E294 in the DE loop resulting in the observed flipped conformation of the $B C$ loop which in turn triggered the flip of the FG loop [29]. Indeed, alignment of the $\mathrm{C}_{\mathrm{H}} 2$ domains from crystal structures of huIgG2 Fc and huIgG2 $\sigma$ Fc suggested that residue P271 in a flipped-out BC loop could clash with K326 in a flipped-in FG loop (Figure 4). A similar flipped-out conformation of the FG loop has since been observed in crystal structures involving huIgG4 Fc [50] (Figure 4). Davies et al. have suggested that sequence differences within the FG loop between huIgG1 and huIgG4 were primarily responsible for the FG loop flip in the latter, and not the absence of H268 [50]. Consistently, one $\mathrm{C}_{\mathrm{H}} 2$ domain in PDB 4D2N [58], a structure of deglycosylated huIgG4 Fc, reveals an FG loop that, although partially disordered, appears to have a flipped-out conformation while the $\mathrm{BC}$ loop is maintained in a flipped-in conformation. The present crystal structure of the huIgG1 $\sigma \mathrm{Fc}$ demonstrated the possibility of the coexistence of a flipped-out BC loop and a flipped-in FG loop. A clash between P271 and K326 was avoided by a rigid body displacement rather than conformational flip of the FG loop away from the flipped BC loop (Figure 4). Furthermore, MD simulations of a single $\mathrm{C}_{\mathrm{H}} 2$ domain of huIgG1 wild-type and mutants were consistent with the hypothesis that positions 330 and 331 are of primary importance to the conformational stability of the FG loop. The simulations showed that the SS (A330S P331S) mutations dramatically increase the flexibility of the FG loop even in the absence of the H268A mutation. Also, just the H268A mutation, in the absence of the FG loop mutations, only marginally increases the flexibility of the two loops relative to wild-type.

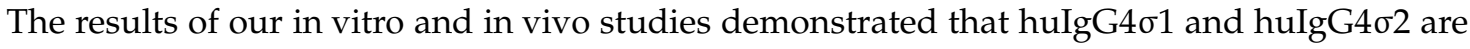
more silent than huIgG4 PAA as discussed above. Given that all the mutations for these variants were localized to the lower hinge region (Figure 2) and that structurally the dispositions of the BC and FG loops were identical to those observed in structures of wild-type huIgG4 Fc (Figure 4), these mutations could function either by directly disrupting hinge:receptor interactions or indirectly by altering lower hinge backbone conformation. Structures of huIgG1 in complex with Fc $\gamma$ RI and Fc $\gamma$ RIIIa have shown the importance for L235 in receptor engagement (Figure S6). This residue was mutated to alanine in both huIgG1 $\sigma$ as well as huIgG4 $1 / 2$, and this mutation likely has a direct effect on receptor engagement. In contrast, an altered conformation of ordered lower hinge residues $\mathrm{N}$-terminal to

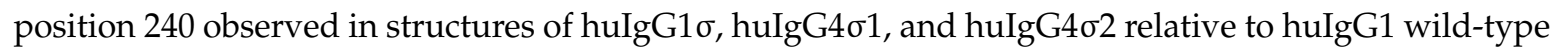
was like that observed in structures of huIgG1 P238D and huIgG1 C220S, E233D, G237D, P238D, H268D, P271G, A330R in complex with Fc $\gamma$ RIlb (Figure 3). All Fc variants demonstrating this kinked conformation commonly share mutation of a conserved proline at position 238 and have an altered ability to engage Fc receptor. Thus, although P238 does make contacts with Fc receptor, it is likely that this residue also plays an important indirect role in maintaining receptor affinity, biasing the structure of the lower hinge toward a conformation competent for receptor engagement.

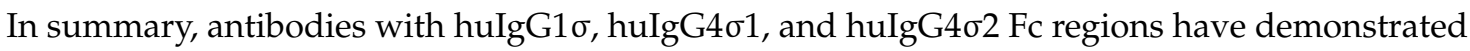
minimal Fc $\gamma$ R interactions by in vitro and in vivo methods. Immunogenicity, developability, and PK risks of these variants have been evaluated and determined to be comparable to that the huIgG1 WT

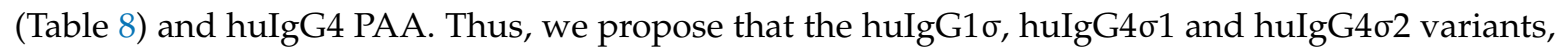
which offer several IgG subtype choices, be considered along with the existing silent Fc structures for incorporation into antibody based biotherapeutic molecules. 
Table 8. Summary of Silent Fc Designs.

\begin{tabular}{|c|c|c|c|c|c|c|c|c|}
\hline & IgG1 WT & IgG1 AA & IgG1 $\sigma$ & IgG1 FES & $\operatorname{IgG} 2 \sigma$ & IgG4 PAA & $\operatorname{IgG4\sigma 1}$ & IgG4\%2 \\
\hline Number of Mutations & 0 & 2 & 7 & 3 & 7 & 3 & 5 & 6 \\
\hline $\begin{array}{l}\text { Lack of Fc Immune } \\
\text { Functions }{ }^{1}\end{array}$ & + & $++/+$ & ++++ & $++/+++$ & ++++ & +++ & ++++ & ++++ \\
\hline Developability $^{2}$ & ++++ & ++++ & ++++ & ++++ & +++ & ++++ & ++++ & ++++ \\
\hline $\mathrm{PK}^{3}$ & ++++ & +++ & ++++ & ++++ & +++ & ++++ & ++++ & ++++ \\
\hline $\begin{array}{l}\text { Low Immunogenicity } \\
\text { Risk }^{4} \text { (in silico) }\end{array}$ & ++++ & ++++ & ++++ & ND & +++ & ++++ & ++++ & +++ \\
\hline $\begin{array}{c}\text { Low PBMC } \\
\text { Immunogenicity } 5\end{array}$ & ++++ & ++++ & ND & ND & ++++ & ++++ & ND & ND \\
\hline
\end{tabular}

ND indicates no data. ${ }^{1}$ Lack of Fc Immune Functions was determined collectively by Fc $\gamma$ R binding, ADCC, ADCP, $\mathrm{CDC}$, in vivo $\mathrm{T}$ cell activation, and in vivo tumor cell inhibition studies. The least silent is denoted by + and ranges to ++++ as the most silent. ${ }^{2}$ Developability was determined by thermal stability, stability of concentrated IgG samples and stability after low $\mathrm{pH}$ treatment. Good is + , intermediate is +++ , and best is.$++++{ }^{3}$ PK was performed in human FcRn transgenic mice and in cynomolgus monkeys. Variants with longer half-life are denoted ++++, and ones with slightly shorter half-life are shown as +++. ${ }^{4}$ Low Immunogenicity Risk was predicted using a $\mathrm{T}$ cell epitope analyses software. ++++ indicates low risk and +++ is medium to low risk. ${ }^{5}$ Low PBMC immunogenicity data from a previous report are included because huIgG1 $\sigma$ and huIgG4 $\sigma$ variants have very similar sequences. ++++ indicates low risk.

\section{Materials and Methods}

\subsection{Antibodies}

$\mathrm{Ab} 1$ is a huIgG1 kappa antibody specific for tumor necrosis factor alpha (TNF $\alpha)$; $\mathrm{Ab2}$ is a huIgG1 kappa monoclonal antibody specific for F glycoprotein of Respiratory Syncytial Virus (RSV); Ab3 is a huIgG1 bispecific antibody targeted against RSV and glycoprotein gp120 of the human immunodeficiency virus (HIV) envelope; $\mathrm{Ab} 4$ is an anti-mouse CD3e-chain Ab, 145-2C11, and Ab5 is TA99, an anti-gp75 antibody which targets gp75 antigen on B16F10 melanoma cells [45,59]. H435A is a mutation which reduces binding to FCRn [60]. LoF refers to low fucosylated IgG which has increased ADCC/ADCP effector function in vitro and in vivo [42]. R10Z8E9 is a mouse anti-huIgG antibody that is specific for the $\mathrm{C}_{\mathrm{H}} 2$ domain [61]. All antibodies were produced and purified at Sino Biologics by transient HEK cell transfection. Antibodies were purified using standard protein A chromatography and confirmed to be greater than $95 \%$ purity and low in endotoxin prior to experiments. The bispecific antibody was made using the DuoBody ${ }^{\circledR}$ technology (Genmab, Copenhagen, Denmark) [62], and confirmed to be greater than $95 \%$ purity.

\subsection{Cell Lines}

K2 cells are Sp2/0 mouse myeloma cells which express a mutant, transmembrane form of human $\mathrm{TNF} \alpha[41,63]$. K2 cells were cultured at $37{ }^{\circ} \mathrm{C}, 5 \% \mathrm{CO}_{2}$, in Iscove's Modified Dulbecco's Medium (IMDM) with GlutaMAX and 5\% $(v / v)$ heat-inactivated fetal bovine serum (FBS), $1 \times$ non-essential amino acids (NEAA), $1 \times$ sodium pyruvate, $0.5 \mu \mathrm{g} / \mathrm{mL}$ mycophenolic acid, $2.5 \mu \mathrm{g} / \mathrm{mL}$ hypoxanthine, and $50 \mu \mathrm{g} / \mathrm{mL}$ xanthine (MHX). Media components were purchased from Life Technologies (as 100×, Carlsbad, CA, USA) and the MHX components from Sigma (St. Louis, MO, USA).

B16F10 mouse melanoma cell line was obtained from the American Tissue Culture Collection. Cells were cultured in RPMI 1640 supplemented with 10\% $(v / v)$ FBS, $1 \times$ NEAA, and $1 \times$ sodium pyruvate.

\subsection{Fc Gamma Receptor (Fc $\gamma R$ ) Binding}

Binding of Ab1 variants to human Fc $\gamma$ Rs was assessed using an AlphaScreen (PerkinElmer, Boston, MA, USA) bead assay in a competition binding format. Fc $\gamma$ Rs were purchased from R\&D Systems or Sino Biological Inc. (Beijing, China). Since the outcome for huIgG with a silent Fc in a Fc $\gamma R$ binding assay may be a negative result, assay sensitivity was increased by introducing avidity to the test samples via cross-linking. This was achieved using a goat $\mathrm{F}\left(\mathrm{ab}^{\prime}\right)_{2}$ anti-huIgG $\mathrm{F}\left(\mathrm{ab}^{\prime}\right)_{2}$-specific 
fragment (Jackson ImmunoResearch, West Grove, PA, USA) in 1:1 molar ratio with the test huIgGs. Cross-linked test antibodies (Thermo Fisher Scientific, Waltham, USA) were added to Corning white half-well 96-well assay plates (Corning Inc., Corning, NY, USA) at the designated concentrations in competition with biotin-labeled huIgG Fc fragment (biot-Fc) at either $1 \mu \mathrm{g} / \mathrm{mL}$ (for Fc $\gamma \mathrm{RI}$, -RIIa, and -RIIb assays) or $5 \mu \mathrm{g} / \mathrm{mL}$ (for Fc $\gamma$ RIIIa assays). Biotinylated Fc fragment was used to prevent binding to the biot-Fc by the test article cross-linker described above. Fc $\gamma$ Rs as specified were added to a $200 \mathrm{ng} / \mathrm{mL}$ final concentration. Nickel chelate acceptor beads were added; followed by streptavidin donor beads. Plates were covered with foil adhesive plate sealers to protect from light, and placed on an orbital plate shaker with gentle shaking for $45 \mathrm{~min}$ at room temperature (RT). Subsequently, plates were read on the EnVision multi-label plate reader (Perkin-Elmer), and data plotted with GraphPad Prism v6.0 software (GraphPad, San Diego, CA, USA).

\subsection{Competitive Binding to Recombinant Human FcRn}

A competitive binding assay was used to assess relative affinities of different antibody samples to recombinant human FcRn (in-house expressed with transmembrane and cytoplasmic domains of FcRn replaced with a poly-histidine affinity tag). Ninety-six-well copper-coated plates (Thermo Scientific) were used to capture FcRn-His6 at $4 \mu \mathrm{g} / \mathrm{mL}$ in PBS, after which plates were washed with $0.15 \mathrm{M} \mathrm{NaCl}$, $0.02 \%(w / v)$ Tween 20 , and then incubated with blocking reagent $(0.05 \mathrm{M}$ MES, $0.025 \%(w / v)$ bovine serum albumin, $0.001 \%(w / v)$ Tween-20, $\mathrm{pH}$ 6.0, 10\% $(v / v)$ ChemiBlocker from Sigma-Aldrich, St. Louis, MO, USA. Plates were washed and serial dilutions of competitor test antibody in blocking reagent were added to plates in the presence of a fixed $4 \mu \mathrm{g} / \mathrm{mL}$ concentration of an indicator antibody (a biotinylated huIgG1). Plates were incubated at RT for $1 \mathrm{~h}$, washed 3 times, and then incubated with a 1:10,000 dilution of HRP (Jackson ImmunoResearch Laboratories) at room temperature (RT) for $30 \mathrm{~min}$ to bind biotinylated antibody. Plates were washed and bound streptavidin-HRP was detected by adding TMB peroxidase substrate (Fitzgerald, Acton, MA, USA). Color development was stopped by addition of $0.5 \mathrm{M} \mathrm{HCl}$. Optical densities were determined with a SpectraMax Plus384 plate reader (Molecular Devices, Sunnyvale, CA, USA) at $450 \mathrm{~nm}$ wavelength, and data plotted with GraphPad Prism v6.0 software.

\subsection{Antibody-Dependent Cell-Mediated Cytotoxicity (ADCC)}

Peripheral mononuclear cells (PBMCs) were isolated from heparinized blood from in-house donors. Eighty (80) $\mathrm{mL}$ of blood from 2 donors were typically used per experiment. Blood was diluted 2-fold with PBS and $30 \mathrm{~mL}$ was layered over $15 \mathrm{~mL}$ of Ficoll-Paque (Perkin-Elmer, Waltham, MA, USA) in a $50 \mathrm{~mL}$ conical centrifuge tube. Tubes were centrifuged at $400 \times g$ at RT for $30 \mathrm{~min}$. The upper plasma supernatant was removed and the interface white cell layer was collected and washed twice with PBS to remove Ficoll and majority of platelets. Cells were resuspended in IMDM-5\% heat inactivated FBS with $1 \times$ sodium pyruvate, $1 \times$ NEAA, and $1 \times$ penicillin-streptomycin $(100 \times$ from Life Technologies, Carlsbad, CA, USA) for culturing overnight at $37^{\circ} \mathrm{C}, 5 \% \mathrm{CO}_{2}$.

$\mathrm{K} 2$ cells were used as target cells at a ratio of 50 effector cells per 1 target cell. Target cells were pre-labeled with BATDA (bis (acetoxymethyl) $2,2^{\prime}: 6^{\prime}, 2^{\prime \prime}$-terpyridine- $6,^{\prime \prime}$-dicarboxylate, DELFIA ${ }^{\circledR}$ EuTDA, PerkinElmer) for $25 \mathrm{~min}$ at $37^{\circ} \mathrm{C}$, washed 3 times in culture medium (IMDM with Glutamax, $10 \%(v / v)$ heat-inactivated Fetal Bovine serum (FBS), $1 \times$ non-essential amino acids (NEAA), $1 \times$ sodium pyruvate, $1 \times$, penicillin-streptomycin; all from Life Technologies and resuspended in culture medium. Target cells $\left(2 \times 10^{5}\right.$ cells $\left./ \mathrm{mL}, 50 \mu \mathrm{L}\right)$ were added to test antibody $(100 \mu \mathrm{L})$ in 96-well U-bottom plates, then effector cells $\left(1 \times 10^{7}\right.$ cells $\left./ \mathrm{mL}, 50 \mu \mathrm{L}\right)$ were added. Plates were centrifuged at $200 \times g$ for $3 \mathrm{~min}$, incubated at $37^{\circ} \mathrm{C}$ for $2 \mathrm{~h}$, and then centrifuged again at $200 \times g$ for $3 \mathrm{~min}$. A total of $20 \mu \mathrm{L}$ of supernatant was removed per well, and cell lysis was measured by the addition of $200 \mu \mathrm{L}$ of the DELFIA Europium-based reagent (PerkinElmer). Fluorescence was measured using an Envision 2101 Reader (PerkinElmer). Data were normalized to maximal cytotoxicity with $0.7 \%(w / v)$ Triton X-100 (Sigma-Aldrich, St. Louis, MO, USA) or 10\% $(v / v)$ Lysis Buffer (DELFIA ${ }^{\circledR}$ 
PerkinElmer) and minimal lysis using target cells in the absence of any Ab. Samples were tested in duplicate. Percent specific lysis was calculated to be (sample lysis - minimal lysis) divided by (maximal lysis-minimal lysis) $\times 100$. Data were fit to a sigmoidal dose-response model using GraphPad Prism v6.0 software.

\subsection{Antibody-Dependent Cellular Phagocytosis (ADCP)}

Monocytes were isolated from human PBMCs using a Monocyte Isolation Kit (Miltenyi, Auburn, AL, USA) and differentiated into macrophages for 1 week by culturing with $10 \mathrm{ng} / \mathrm{mL}$ recombinant human granulocyte-macrophage colony-stimulating factor (GM-CSF) and $10 \mathrm{ng} / \mathrm{mL}$ recombinant human IL-4 (both from R \& D Systems, Minneapolis, MN, USA) in IMDM with Glutamax, 10\% heat-inactivated FBS, $1 \times$ NEAA, $1 \times$ sodium pyruvate, $1 \times$ penicillin-streptomycin. Macrophages were labeled with PKH26 (fluorescent dye for cell membrane, Sigma) and K2 cells were labeled with PKH67 (Sigma). Labeled cells in IMDM-10\% $(v / v)$ heat-inactivated FBS media without phenol red were incubated for $5 \mathrm{~h}$ with a macrophage to $\mathrm{K} 2$ cell ratio of 1 effector to 1 target cell in the presence of test antibody. Two-color flow cytometry analyses were performed with a MACSQuant Flow Cytometer (Miltenyi) using optimal compensation in the B1 (PKH67) and B2 (PKH26) channels and gating on single cells. Dual-labeled cells (PKH26+/PKH67+) were considered to represent phagocytosis of K2 target cells by macrophages. Percent ADCP or phagocytosis of target cells was calculated to be $100 \times$ number of dual-labeled cells (macrophage + target) divided by the total number of target cells in the population (phagocytosed + non-phagocytosed) after $>50,000$ cell counts. The percent specific ADCP was obtained by subtracting from each sample the background value (macrophage + target incubated without $\mathrm{Ab}$ ) [5].

\subsection{Complement-Dependent Cytotoxicity (CDC)}

K2 cells were used as target cells for CDC assays. A total of $50 \mu \mathrm{L}$ of cells was added to wells of a 96-well plates for a final concentration of $8 \times 10^{4}$ cells per well in IMDM with Glutamax, 10\% $(w / v)$ heat-inactivated PBS, $1 \times$ NEAA, $1 \times$ sodium pyruvate, $1 \times$ penicillin-streptomycin. An additional $50 \mu \mathrm{L}$ was added to the wells with or without test $\mathrm{Abs}$ and plates were incubated at $37{ }^{\circ} \mathrm{C}$ for $2 \mathrm{~h}$. A total of $50 \mu \mathrm{L}$ of $10 \%(w / v)$ rabbit complement (Invitrogen, Carlsbad, CA, USA) was added to the wells, and plates were incubated for $20 \mathrm{~min}$ at $37^{\circ} \mathrm{C}$. All samples were performed in triplicate. The plates were centrifuged at $200 \times g$ for $3 \mathrm{~min}, 50 \mu \mathrm{L}$ of supernatant was removed to separate plates, and CDC was measured with a LDH cytotoxicity detection kit (Roche, Indianapolis, IN, USA). Absorbance was measured using a Spectra Max Plus 384 (PerkinElmer). Data were fit to a sigmoidal dose-response model using GraphPad Prism v6.0 software. Maximal cytotoxicity was obtained with Triton X-100 (Sigma-Aldrich) and spontaneous release with cells and complement alone. Specific cell lysis was calculated as follows: Cytotoxicity $(\%)=100 \times$ (optical density (OD) of sample - OD of spontaneous release)/(OD of maximal lysis - OD of spontaneous release).

\subsection{Animals}

The Fc $\gamma$ R-humanized (Fc $\gamma$ R-hu) mice used in the T-cell activations studies express the different human Fc $\gamma$ Rs: CD16a (Fc $\gamma$ RIIIa), CD16b (Fc $\gamma$ RIIIb), CD32a (Fc $\gamma$ RIIa), CD32b (Fc $\gamma$ RIIb) and CD64 $(\mathrm{Fc} \gamma \mathrm{R} 1)$ and their endogenous mouse Fc $\gamma$ Rs have been inactivated [43]. Three strains of these C57BL/6 mice (8-10 weeks old) were used: $F_{c} \gamma R \alpha$ null females, Fc $\gamma$ R-hu hemizygous (hemi) females, and Fc $\gamma$ R-hu homozygous (homo) females.

Human FcRn transgenic animals (8-10 weeks old) used in PK studies were derived from C57BL/6 mice [64]. Tg32 mice (B6.Cg-Fcgrt ${ }^{\text {tmLDcr }}$ Tg(FCGRT)32Dcr from The Jackson Laboratory) have their endogenous mouse FcRn $\alpha$ gene knocked out and are transgenic with the human FcRn $\alpha$ gene under the control of the native human gene promoter $[65,66]$. The FcRn transgenic strain show clinical chemical parameters like those found in wild-type mice except for endogenous huIgG levels, which are greatly reduced in these mice [67]. Tg32 hemi referred to mice hemizygous for the FcRn transgene, 
the latter derived by mating homozygous transgenic mice with FcRn $\alpha$ knockout mice (transgene copy number reduced by half).

Naive cynomolgus monkeys used in the PK study at WuXi AppTec., (Suzhong, China) were approximately 2 to 3.5 years old and weighed between 2.5 and $3.0 \mathrm{~kg}$.

\section{9. $T$ Cell Activation}

Fc $\gamma$ R-hu mice were used in the in vivo binding and $\mathrm{T}$ cell activation studies. The preliminary study was done with three strains of mice (8-10 weeks old): FcR $\alpha$ null females, Fc $\gamma$ R-hu (hemi) females, and Fc $\gamma$ R-hu homozygous (homo) females. Test antibody was injected into the intraperitoneal cavity of the mice at $0.5 \mathrm{mg} / \mathrm{kg}, 10 \mathrm{~mL} / \mathrm{kg}$. Approximately $24 \mathrm{~h}$ later, mice were euthanized by $\mathrm{CO}_{2}$ asphyxiation and their spleens removed and placed into tubes containing cold RPMI-1640, 5\% $(v / v)$ heat-inactivated FBS, $1 \%(w / v)$ L-glutamine.

Mouse splenocytes were prepared from 3 to 6 mice as single-cell suspensions from each individual spleen on the day of harvest. They were washed with media, followed by anucleated red blood cell depletion using hypotonic RBC lysis solution (eBiosciences). Splenocytes were analyzed by flow cytometry for cell surface expression of CD25 and CD69 T cell activation markers. Cells were resuspended in staining buffer consisting of PBS for viability staining (IR Live Dead, Invitrogen), washed, and then incubated with anti-CD16/32 (2.4G2, BD Biosciences, San Jose, CA, USA) to block nonspecific binding. Immunostaining was done in the presence of APC-CD25, FITC-CD8a, PE-CD4, PerCP-CD69, PE-Vio770-CD3ع (BD Biosciences, Biolegend or Miltenyi) at $4{ }^{\circ} \mathrm{C}$ for $30 \mathrm{~min}$ protected from light, and followed by two washes.

Cells were analyzed on the MACSQuant Analyzer (Miltenyi). Analyses of the multivariate data were performed using FlowJo v10 software (FlowJo, Ashland, OR, USA). The percent of CD8+ and CD3+ cells that were also positive for CD25 (or CD69) expression were based on data collected with greater than 50,000 cells from each sample.

\subsection{B16F10 Syngeneic Tumor Model}

Fc $\gamma$ R-hu mice (8-10 weeks old female) were used for the syngeneic mouse lung tumor model. B16F10 tumor cells were intravenously injected into tail vein at $2 \times 10^{5}$ cells $/$ mouse, $0.2 \mathrm{~mL}$ of $1 \times 10^{6}$ cells $/ \mathrm{mL}$ in PBS [44,45]. At 30-60 min post IV injection, $0.2 \mathrm{~mL}$ of the test antibody sample was injected into the peritoneum. Antibody doses were given on day $0,2,4,7,9$ and 11 . On day 21 , the mice were sacrificed and the lungs were weighed and scored for the number of metastases. The lung tumor index was determined by lung weight and tumor grade [68].

Tumor index $=$ lung weight $\times$ grade for animal tumor Grading:

1. Less than 10 tumor foci

2. 10-100 tumor foci

2.5. More than 100 foci, but countable

3. One lobe of the lung is full of tumor

4. Both lobes are full of tumor

5. Lungs are full of tumor and tumor growing out into cavities

\subsection{Pharmacokinetics (PK)}

For mouse antibody PK studies, female Tg32 hemi mice were injected with test antibody intravenously via tail vein at a dose of $2 \mathrm{mg} / \mathrm{kg}$ into 3 or 4 animals per group. Serial retro-orbital bleeds were obtained from $\mathrm{CO}_{2}$-anesthesized mice at indicated time points and terminal bleed was taken by cardiac puncture. After $30 \mathrm{~min}$ at RT, blood samples were centrifuged at $2500 \mathrm{rpm}$ for $15 \mathrm{~min}$ and serum collected for analyses. All PK studies were approved by the Institutional Animal Care and Use Committee at Janssen Research \& Development, LLC (Spring House, PA, USA). 
An electrochemiluminescent immunoassay was used to measure human antibody concentration in mouse sera. Briefly, Streptavidin Gold multiarray 96-well plates 96-well plates (Meso Scale Discovery, Rockville, MD, USA) were coated with $50 \mu \mathrm{L} /$ well of $1 \mu \mathrm{g} / \mathrm{mL}$ biotinylated $\mathrm{F}\left(\mathrm{ab}^{\prime}\right)_{2}$ goat anti-human $\operatorname{IgG}\left(\mathrm{H}+\mathrm{L}\right.$, Jackson Immunochemical) in Starting Block T20 (Thermo Scientific) overnight at $4{ }^{\circ} \mathrm{C}$ and washed with Tris-buffered saline with $0.05 \%(w / v)$ Tween 20 (TBST from Sigma). Standards and serum samples were prepared in sample buffer $(1 \%(w / v)$ bovine serum albumin in TBST and $20 \mathrm{mM}$ EDTA) added to plates and incubated for $2 \mathrm{~h}$ at RT on a shaker. Plates were washed and incubated for $1 \mathrm{~h}$ with $1 \mu \mathrm{g} / \mathrm{mL}$ MSD-Sulfo (ruthenium)-labeled with a pan huIgG1 Ab, R10Z8E9. Plates were washed, $1 \times$ Read buffer T was added and plates were read on the MSD Sector Imager 6000 (Meso Scale Discovery).

Terminal half-life $\left(t_{1 / 2}\right)$ calculations of the elimination phase for PK studies were determined using a 1-phase exponential decay model fitted by linear regression of natural log concentration versus time using Prism version 6.0 software. The least squares nonlinear decay model was weighted by 1 /fitted concentration. Half-life calculations of the elimination phase were determined using the formula $t_{1 / 2}=-\ln 2 / \beta$, where $\beta$ is the slope of the line fitted by the least square regression analysis starting after the first dose.

Monkey PK studies were performed at WuXi Apptec in China. Three animals were IV injected with test antibody at $1.5 \mathrm{mg} / \mathrm{kg}$, and $1 \mathrm{~mL}$ of blood was collected via a cephalic vein at pre-dose, and at day 1, day 3, day 5, day 8, day 15 and day 22 post-dose. Serum samples were prepared and PK analyses were performed at Frontage (Shanghai) using a similar MSD format. Protocols were reviewed and approved by WuXi AppTec Institutional Animal Care and Use Committee (IACUC) prior to procedures (MGMT-011; TECH-030).

\subsection{ImmunoFilter ${ }^{T M}$ Analyses}

The amino acid sequences for the different variants were analyzed in silico using ImmunoFilter ${ }^{\mathrm{TM}}$, an HLA class II-peptide binding prediction tool to predict comparative immunogenicity in humans (v2.7, Xencor, Inc., Monrovia, CA, USA, examples [69-71]). This prediction tool uses an immunochemical data set of peptide agretope binding to class II major histocompatibility complex (MHC) which can assess potential immunogenicity for more than 95\% of U.S. population, based on empirical binding data. Output provided includes raw binding scores for peptides across a sequence of interest, standardized binding scores, binding probabilities to each allelic combination, and summary IScores, which are weighted, population-relevant values. For analyses, peptides from the wild-type and variant sequences with 100\% identity to each other were excluded by application of a tolerance threshold, and only peptides spanning the sequences of interest were included. Resulting IScores were averaged across all loci, and plotted. Higher IScores indicate a higher predicted immunogenic risk (PIR).

\subsection{Developability}

To assess whether antibodies with silent Fc regions would have good manufacturing properties, biophysical analytical tests were performed for thermal stability and solubility.

\subsubsection{Differential Scanning Calorimetry (DSC)}

DSC experiments were performed using a MicroCal Auto VP-capillary DSC system (Malvern Instruments Ltd., Malvern, UK) in which temperature differences between the reference and sample cell were continuously measured and converted to power units. Samples were heated from $25^{\circ} \mathrm{C}$ to $110{ }^{\circ} \mathrm{C}$ at a rate of $1{ }^{\circ} \mathrm{C} / \mathrm{min}$. A pre-scan time of $10 \mathrm{~min}$ and a filtering period of $10 \mathrm{~s}$ were used for each run. DSC measurements were made at sample concentrations of approximately $0.5 \mathrm{mg} / \mathrm{mL}$ in $1 \times$ PBS buffer in duplicate. Analysis of the resulting data was performed using MicroCal Origin 7 software (MicroCal, Northampton, MA, USA). 


\subsubsection{Concentration Assessment}

Antibody samples were concentrated by centrifugation at $2250 \times g$ using Amicon Ultra-15 centrifugal filter units with Ultracel-30 membranes (Sigma-Aldrich). Samples were inspected for signs of precipitation until volumes were reached for a concentration of $40-50 \mathrm{mg} / \mathrm{mL}$. The sequence-predicted absorbance constants $(\mathrm{A} 280 / \mathrm{mg} / \mathrm{mL})$ for each antibody were used to calculate sample concentrations at absorbance $280 \mathrm{~nm}$.

\subsubsection{Dynamic Light Scattering (DLS)}

Particle size and size distributions were determined using DLS on a DynaPro Plate Reader (Wyatt Technologies Corporation, Santa Barbara, CA, USA) at $23{ }^{\circ} \mathrm{C}$. For each analysis, $30 \mu \mathrm{L}$ of each sample at $1 \mathrm{mg} / \mathrm{mL}$ was placed in a 384-well black polystyrene plate with a clear flat bottom (Corning, CLS3540). Triplicate measurements were performed for each sample with each measurement consisting of 20 runs.

\subsubsection{Static Light Scattering (SLS), Thermal Melting (Tm) and Thermal Aggregation (Tagg) Analyses}

Tm was determined for each sample using intrinsic fluorescence with the Uncle instrument (Unchained Labs, Pleasanton, CA, USA). Tagg was assessed by Static Light Scattering (SLS) to monitor protein aggregation using the same instrument. For the combined Tm and Tagg method, antibody was loaded and run with a thermal ramp from 15 to $95^{\circ} \mathrm{C}$; at a ramp rate of $0.3^{\circ} \mathrm{C} / \mathrm{min}$.

\subsubsection{Size Exclusion Chromatography (SEC)}

Samples were separated over a TOSOH TSKgel BioAssist G3SWxL column $(7.8 \mathrm{~mm} \times 30 \mathrm{~cm}$, $5 \mu \mathrm{m}, \mathrm{TOSOH})$ that had been equilibrated with PBS supplemented with $500 \mathrm{mM} \mathrm{NaCl}$, at a flow rate of $0.5 \mathrm{~mL} / \mathrm{min}$ using an Agilent 1100-series HPLC (Agilent Technologies, Santa Clara, CA, USA). A target of 100-200 $\mu \mathrm{g}$ of total protein was injected per run. Peaks were monitored using absorbance at $280 \mathrm{~nm}$. Data analysis of species found in each sample was performed using ChemStation software (Agilent Technologies).

\subsubsection{Low $\mathrm{pH}$ Treatment}

Exposure to low $\mathrm{pH}$ was performed for accelerated stability testing. Protein samples were prepared at a concentration of $1 \mathrm{mg} / \mathrm{mL}$. Samples were dialyzed for $6 \mathrm{~h}$ into $0.05 \mathrm{M}$ sodium acetate buffer, $\mathrm{pH}$ 3.5; then dialyzed for $16 \mathrm{~h}$ in $0.1 \mathrm{M} \mathrm{PBS}, \mathrm{pH} 7.4$, and stored at $4{ }^{\circ} \mathrm{C}$ prior to analyses.

\subsection{Crystallography}

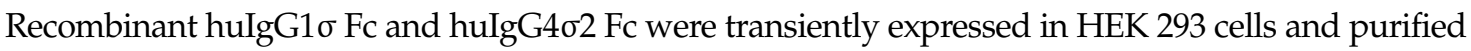
by Protein A affinity chromatography at Sino Biological Inc. (China). Recombinant huIgG4o1 Fc was transiently expressed in 293 Expi cells and purified in two steps using Protein A affinity chromatography and size exclusion chromatography (Superdex 200 PG) at Aldevron (Fargo, ND, USA). Proteins were delivered in $20 \mathrm{mM}$ Tris, $50 \mathrm{mM} \mathrm{NaCl}, \mathrm{pH} 7.5$ at concentrations ranging from 2 to $4 \mathrm{mg} / \mathrm{mL}$. Fc molecules were further concentrated to $10-13 \mathrm{mg} / \mathrm{mL}$ prior to crystallization. Crystallization experiments employed the vapor-diffusion method. Crystallization drops were set up using a Mosquito liquid handling robot (TTP Labtech, Melbourn, UK) in 96-well Corning 3550

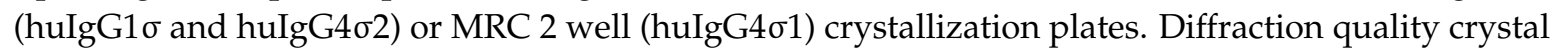
were obtained for all three Fc regions in 9-10\% (w/v) PEG 20,000, $0.1 \mathrm{M}$ sodium acetate, pH 5.5 (reservoir condition for huIgG4 62 additionally contained 5\% (w/v) MPD). Prior to data collection, crystals were cryo-protected in reservoir supplemented with $20 \%(w / v)$ glycerol and flash frozen in liquid $\mathrm{N}_{2}$. X-ray diffraction data for huIgG1 $\sigma$ and huIgG4 $\sigma 1$ were collected on the IMCA-CAT beam line (17-ID) at the Advanced Photon Source (APS) at Argonne National Laboratory equipped with

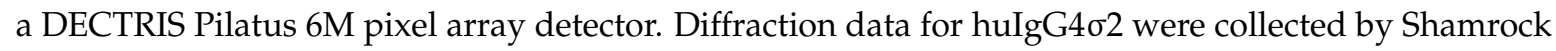


Structures, LLC on the SER-CAT beam line (22-ID) at APS equipped with a Rayonix 300HS CCD detector. All data were processed with the program XDS [72].

Initial phases were determined by the method of molecular replacement with the program Phaser [73] as implemented in the CCP4 suite of programs [74]. Individual $\mathrm{C}_{\mathrm{H}} 2$ and $\mathrm{C}_{\mathrm{H}} 3$ domains

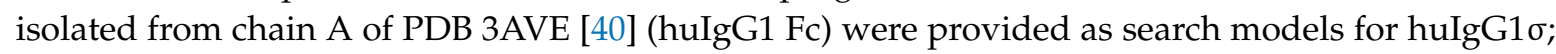

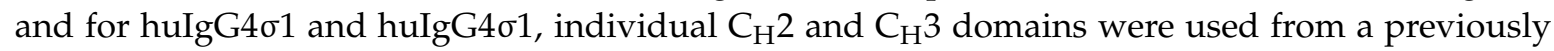
refined internal structure of wild-type huIgG4 Fc. Phaser positioned the equivalent of one Fc dimer in the asymmetric unit in space group $\mathrm{P} 2{ }_{1} 2_{1} 2_{1}$. The structures underwent rounds of rebuilding and refinement with the programs Crystallographic Object-Oriented Toolkit (COOT) [75] and Phenix [76,77] respectively. Data collection and refinement statistics are provided in Table 2. The atomic coordinates and structure factors are archived in the Protein Data Bank under the accession numbers 5W5L, 5W5M, and 5 W5N corresponding to huIgG1 $\sigma \mathrm{Fc}$, huIgG4 $\sigma 1 \mathrm{Fc}$, and huIgG4 $\sigma 2 \mathrm{Fc}$, respectively.

\subsection{Molecular Dynamics Simulations}

Explicit solvent MD simulations were performed on intact $F_{c}$ to investigate the flexibility of BC and FG loops. Two simulations were initiated from the available crystal structures: IgG1 WT using the crystal structure (PDB 3AVE) of IgG1 wild-type Fc and IgG1 $\sigma$ using the crystal structure described here. Additional two simulations were initiated after modelling mutations in the wild-type crystal structure: IgG1-H268A containing H268A mutation and IgG1-SS containing A330S and P331S mutations. The simulations included both chains of $\mathrm{C}_{\mathrm{H}} 2$ and $\mathrm{C}_{\mathrm{H}} 3$ domains, and the glycans present in the corresponding crystal structures. The simulations were set up in the Maestro graphical user interface and run using the Desmond program (multisim version 3.8.5.19 and mmshare version 3.5) [78], both part of the Schrodinger 2016-3 suite [79]. The systems were protonated at neutral pH and centered in an orthorhombic box such that the minimum distance from any protein atom to the box wall was $10 \AA$ A. The box was solvated using SPC [80] water molecules and counter ions were added to neutralize the system. OPLS3 force field [81] was used as the potential energy function for the protein. Replica Exchange Solute Tempering [82] (REST) MD simulations were performed at $300 \mathrm{~K}$ and $1 \mathrm{bar}$ using 16 replicas with the BC (residue numbers 267-273) and FG (residue numbers 322-333) residues of only chain B specified as "hot". REST MD simulations were designed to enhance sampling of the hot subset of the full simulation system. Note that sampling is enhanced only in chain B since chain A loops are cold. To get an idea of the degree by which sampling is enhanced by REST, we compared the backbone fluctuations of the two chains in the $\mathrm{C}_{\mathrm{H}} 2$ domain. Figure $\mathrm{S} 7$ shows that it was advantageous

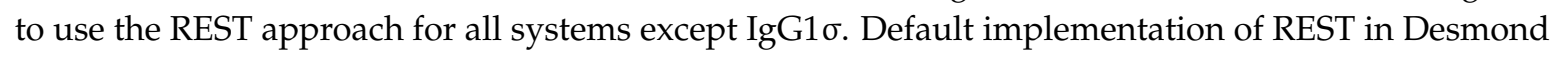
was used for initial equilibration, setting up energy function of each replica, specifying exchange protocol and recording trajectory data. Simulations were performed on AWS (Amazon Web Services) cloud computing platform with each simulation employing 8 NVIDIA Tesla K80 GPU cards (Nvidia, Santa Clara, CA, USA). The production run was 100 nanoseconds long and the final trajectory from each replica contained 4166 conformations saved at an interval of 24 ps. Number of atoms in the simulations was approximately 53,000 and a single simulation took approximately 74 hours. A time step of 2 femtoseconds was used and exchanges were attempted at an interval of 1.2 picoseconds. In all simulations, the acceptance ratio of exchanges between the adjacent replicas was observed to be between 0.2 and 0.4 . The results presented here correspond to the trajectory from the physical replica for which the energy function is unperturbed.

\section{Conclusions}

A requirement for truly silent human Fc designs is evident as more antibodies are being developed

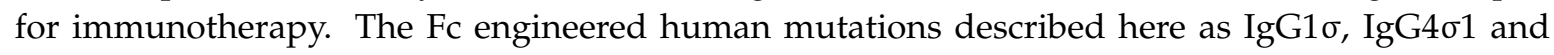
$\operatorname{IgG} 4 \sigma 2$ demonstrate equal or lower immune functionality than the corresponding IgG2 $\sigma$ design. Lack of immune effector function is demonstrated in vitro with Fc $\gamma \mathrm{R}$ binding, cytotoxicity assays, and in vivo with $\mathrm{T}$ cell activation and tumor inhibition studies. Crystal structures and simulations 
of these Fc variants reveal altered conformational preferences within the lower hinge and $\mathrm{BC}$ and FG loops relative to wild-type IgG, providing a structural rationalization for diminished FC receptor engagement. Immunogenicity predictions, pharmacokinetic studies in mice and monkeys, and biophysical analyses also support these novel mutations as optimized silent Fc choices for the development of therapeutic antibodies.

Supplementary Materials: The following are available online at www.mdpi.com/2073-4468/6/3/12/s1; Table S1: Cynomolgus monkey PK parameters for Ab2. Figure S1: Electron density map about lower hinge residues, Figure S2: Altered lower hinge conformation of huIgG1 $\sigma$ is not a requirement of crystal packing, Figure S3: Crystal packing does not prevent huIgG1 $\sigma$ FG loop from adopting a flipped-out conformation, Figure S4: Conformation distribution of P329, Figure S5: Conformation distribution of P271, Figure S6: Interaction of lower hinge and FG loop with Fc $\gamma$ R, Figure S7: REST MD enhances loop sampling.

Acknowledgments: The authors thank protein expression and purification groups and the Structural Biology Group in Antibody Drug Discovery in Biologics Research at Janssen R \& D, LLC, and Sino Biologics, China, for the generation and purification of huIgG reagents used in this study. Additional thanks go to members of Antitope and WuXi AppTec for their efforts in T-cell epitope analysis and PK, respectively, and Lingjie Xu of Janssen Research \& Development, China, for performing the monkey PK data analyses. Special thanks goes to Chichi Huang for continual encouragement, Elena Catterton and Ekaterina Shatalova for diligent patent literature and summary; and to Joani Wendel for formatting this manuscript. Use of the IMCA-CAT beamline 17-ID at the Advanced Photon Source was supported by the companies of the Industrial Macromolecular Crystallography Association through a contract with Hauptman-Woodward Medical Research Institute. This research used resources of the Advanced Photon Source, a U.S. Department of Energy (DOE) Office of Science User Facility operated for the DOE Office of Science by Argonne National Laboratory under Contract No. DE-AC02-06CH11357.

Author Contributions: S.H.T. and S.G.M. designed and performed research, collected, analyzed and interpreted data, performed statistical analysis, and wrote the manuscript; A.A.A. designed and conducted crystallography studies and contributed to manuscript writing; S.S. performed the molecular simulations and contributed to manuscript writing; R.E. and D.S. designed and performed the DSC experiments and data analyses; X.L. performed the high concentration stability and SEC experiments and data analyses; A.G. performed the thermal stability, colloidal stability and DLS experiments and data analyses; S.-J.W. conceived and designed the biophysical analysis experiments and contributed to biophysical part of manuscript; R.D. performed the animal PK studies; G.L.G. advised on crystallography, modeling strategy, and edited manuscript; J.L. advised on crystallography and modeling strategy; M.L.C. interpreted data, contributed to writing and editing the manuscript; B.J.S. designed the strategy for antibody mutations, interpreted data and contributed to writing of manuscript.

Conflicts of Interest: Janssen Research \& Development, LLC provided funding for the research. All authors are employees of Janssen Research \& Development, LLC.

\section{References}

1. Gergely, J.; Sarmay, G.; Rajnavolgyi, E. Regulation of antibody production mediated by Fc gamma receptors, IgG binding factors, and IgG Fc-binding autoantibodies. Crit. Rev. Biochem. Mol. Biol. 1992, 27, $191-225$. [CrossRef] [PubMed]

2. Roopenian, D.C.; Akilesh, S. FcRn: The neonatal Fc receptor comes of age. Nat. Rev. Immunol. 2007, 7, 715-725. [CrossRef] [PubMed]

3. Strohl, W.R. Optimization of Fc-mediated effector functions of monoclonal antibodies. Curr. Opin. Biotechnol. 2009, 20, 685-691. [CrossRef] [PubMed]

4. Shields, R.L.; Namenuk, A.K.; Hong, K.; Meng, Y.G.; Rae, J.; Briggs, J.; Xie, D.; Lai, J.; Stadlen, A.; Li, B.; et al. High resolution mapping of the binding site on human IgG1 for Fc gamma RI, Fc gamma RII, Fc gamma RIII, and FcRn and design of IgG1 variants with improved binding to the Fc gamma R. J. Biol. Chem. 2001, 276, 6591-6604. [CrossRef] [PubMed]

5. Lazar, G.A.; Dang, W.; Karki, S.; Vafa, O.; Peng, J.S.; Hyun, L.; Chan, C.; Chung, H.S.; Eivazi, A.; Yoder, S.C.; et al. Engineered antibody Fc variants with enhanced effector function. Proc. Natl. Acad. Sci. USA 2006, 103, 4005-4010. [CrossRef] [PubMed]

6. Stavenhagen, J.B.; Gorlatov, S.; Tuaillon, N.; Rankin, C.T.; Li, H.; Burke, S.; Huang, L.; Vijh, S.; Johnson, S.; Bonvini, E.; et al. Fc optimization of therapeutic antibodies enhances their ability to kill tumor cells in vitro and controls tumor expansion in vivo via low-affinity activating Fcgamma receptors. Cancer Res. 2007, 67, 8882-8890. [CrossRef] [PubMed]

7. Czajkowsky, D.M.; Hu, J.; Shao, Z.; Pleass, R.J. Fc-fusion proteins: New developments and future perspectives. EMBO Mol. Med. 2012, 4, 1015-1028. [CrossRef] [PubMed] 
8. Pollreisz, A.; Assinger, A.; Hacker, S.; Hoetzenecker, K.; Schmid, W.; Lang, G.; Wolfsberger, M.; Steinlechner, B.; Bielek, E.; Lalla, E.; et al. Intravenous immunoglobulins induce CD32-mediated platelet aggregation in vitro. Br. J. Dermatol. 2008, 159, 578-584. [CrossRef] [PubMed]

9. Kontermann, R.E.; Brinkmann, U. Bispecific antibodies. Drug Discov. Today 2015, 20, 838-847. [CrossRef] [PubMed]

10. Daeron, M. Fc receptor biology. Ann. Rev. Immunol. 1997, 15, 203-234. [CrossRef] [PubMed]

11. Labrijn, A.F.; Aalberse, R.C.; Schuurman, J. When binding is enough: Nonactivating antibody formats. Curr. Opin. Immunol. 2008, 20, 479-485. [CrossRef] [PubMed]

12. Strohl, W.R. Fusion proteins for half-life extension of biologics as a strategy to make biobetters. BioDrugs 2015, 29, 215-239. [CrossRef] [PubMed]

13. Tao, M.H.; Morrison, S.L. Studies of aglycosylated chimeric mouse-human IgG. Role of carbohydrate in the structure and effector functions mediated by the human IgG constant region. J. Immunol. 1989, 143, 2595-2601. [PubMed]

14. Sazinsky, S.L.; Ott, R.G.; Silver, N.W.; Tidor, B.; Ravetch, J.V.; Wittrup, K.D. Aglycosylated immunoglobulin G1 variants productively engage activating Fc receptors. Proc. Natl. Acad. Sci. USA 2008, 105, 20167-20172. [CrossRef] [PubMed]

15. Hristodorov, D.; Fischer, R.; Linden, L. With or without sugar? (A)glycosylation of therapeutic antibodies. Mol. Biotechnol. 2013, 54, 1056-1068. [CrossRef] [PubMed]

16. Jacobsen, F.W.; Stevenson, R.; Li, C.; Salimi-Moosavi, H.; Liu, L.; Wen, J.; Luo, Q.; Daris, K.; Buck, L.; Miller, S.; et al. Engineering an IgG scaffold lacking effector function with optimized developability. J. Biol. Chem. 2017, 292, 1865-1875. [CrossRef] [PubMed]

17. Chappel, M.S.; Isenman, D.E.; Everett, M.; Xu, Y.Y.; Dorrington, K.J.; Klein, M.H. Identification of the Fc gamma receptor class I binding site in human IgG through the use of recombinant IgG1/IgG2 hybrid and point-mutated antibodies. Proc. Natl. Acad. Sci. USA 1991, 88, 9036-9040. [CrossRef] [PubMed]

18. Smith, S.L. Ten years of orthoclone OKT3 (muromonab-CD3): A review. J. Transpl. Coord. Off. Publ. N. Am. Transpl. Coord. Organ. 1996, 6, 109-119, quiz 120-101.

19. Alegre, M.L.; Peterson, L.J.; Xu, D.; Sattar, H.A.; Jeyarajah, D.R.; Kowalkowski, K.; Thistlethwaite, J.R.; Zivin, R.A.; Jolliffe, L.; Bluestone, J.A. A non-activating “humanized” anti-CD3 monoclonal antibody retains immunosuppressive properties in vivo. Transplantation 1994, 57, 1537-1543. [CrossRef] [PubMed]

20. Bruhns, P.; Iannascoli, B.; England, P.; Mancardi, D.A.; Fernandez, N.; Jorieux, S.; Daeron, M. Specificity and affinity of human Fcgamma receptors and their polymorphic variants for human IgG subclasses. Blood 2009, 113, 3716-3725. [CrossRef] [PubMed]

21. Ravetch, J.V.; Kinet, J.P. Fc receptors. Ann. Rev. Immunol. 1991, 9, 457-492. [CrossRef] [PubMed]

22. Nimmerjahn, F.; Ravetch, J.V. Divergent immunoglobulin G subclass activity through selective Fc receptor binding. Science 2005, 310, 1510-1512. [CrossRef] [PubMed]

23. Brezski, R.J.; Georgiou, G. Immunoglobulin isotype knowledge and application to Fc engineering. Curr. Opin. Immunol. 2016, 40, 62-69. [CrossRef] [PubMed]

24. Alegre, M.L.; Collins, A.M.; Pulito, V.L.; Brosius, R.A.; Olson, W.C.; Zivin, R.A.; Knowles, R.; Thistlethwaite, J.R.; Jolliffe, L.K.; Bluestone, J.A. Effect of a single amino acid mutation on the activating and immunosuppressive properties of a "humanized" OKT3 monoclonal antibody. J. Immunol. 1992, 148, 3461-3468. [PubMed]

25. Xu, D.; Alegre, M.L.; Varga, S.S.; Rothermel, A.L.; Collins, A.M.; Pulito, V.L.; Hanna, L.S.; Dolan, K.P.; Parren, P.W.; Bluestone, J.A.; et al. In vitro characterization of five humanized OKT3 effector function variant antibodies. Cell. Immunol. 2000, 200, 16-26. [CrossRef] [PubMed]

26. Mueller, J.P.; Giannoni, M.A.; Hartman, S.L.; Elliott, E.A.; Squinto, S.P.; Matis, L.A.; Evans, M.J. Humanized porcine VCAM-specific monoclonal antibodies with chimeric IgG2/G4 constant regions block human leukocyte binding to porcine endothelial cells. Mol. Immunol. 1997, 34, 441-452. [CrossRef]

27. An, Z.; Forrest, G.; Moore, R.; Cukan, M.; Haytko, P.; Huang, L.; Vitelli, S.; Zhao, J.Z.; Lu, P.; Hua, J.; et al. IgG2m4, an engineered antibody isotype with reduced $F_{c}$ function. MAbs 2009, 1, 572-579. [CrossRef] [PubMed]

28. Oganesyan, V.; Gao, C.; Shirinian, L.; Wu, H.; Dall'Acqua, W.F. Structural characterization of a human Fc fragment engineered for lack of effector functions. Acta Crystallogr. Sect. D Biol. Crystallogr. 2008, 64, 700-704. [CrossRef] [PubMed] 
29. Vafa, O.; Gilliland, G.L.; Brezski, R.J.; Strake, B.; Wilkinson, T.; Lacy, E.R.; Scallon, B.; Teplyakov, A.; Malia, T.J.; Strohl, W.R. An engineered fc variant of an IgG eliminates all immune effector functions via structural perturbations. Methods 2014, 65, 114-126. [CrossRef] [PubMed]

30. Dillon, T.M.; Ricci, M.S.; Vezina, C.; Flynn, G.C.; Liu, Y.D.; Rehder, D.S.; Plant, M.; Henkle, B.; Li, Y.; Deechongkit, S.; et al. Structural and functional characterization of disulfide isoforms of the human IgG2 subclass. J. Biol. Chem. 2008, 283, 16206-16215. [CrossRef] [PubMed]

31. Thakkar, S.V.; Sahni, N.; Joshi, S.B.; Kerwin, B.A.; He, F.; Volkin, D.B.; Middaugh, C.R. Understanding the relevance of local conformational stability and dynamics to the aggregation propensity of an $\operatorname{IgG1}$ and IgG2 monoclonal antibodies. Protein Sci. Publ. Protein Soc. 2013, 22, 1295-1305. [CrossRef] [PubMed]

32. Wypych, J.; Li, M.; Guo, A.; Zhang, Z.; Martinez, T.; Allen, M.J.; Fodor, S.; Kelner, D.N.; Flynn, G.C.; Liu, Y.D.; et al. Human IgG2 antibodies display disulfide-mediated structural isoforms. J. Biol. Chem. 2008, 283, 16194-16205. [CrossRef] [PubMed]

33. Schlothauer, T.; Herter, S.; Koller, C.F.; Grau-Richards, S.; Steinhart, V.; Spick, C.; Kubbies, M.; Klein, C.; Umana, P.; Mossner, E. Novel human IgG1 and IgG4 Fc-engineered antibodies with completely abolished immune effector functions. Protein Eng. Des. Sel. PEDS 2016, 29, 457-466. [CrossRef] [PubMed]

34. Escobar-Cabrera, E.; Lario, P.; Baardsnes, J.; Schrag, J.; Durocher, Y.; Dixit, S. Asymmetric Fc engineering for bispecific antibodies with reduced effector function. Antibodies 2017, 6, 7. [CrossRef]

35. Angal, S.; King, D.J.; Bodmer, M.W.; Turner, A.; Lawson, A.D.; Roberts, G.; Pedley, B.; Adair, J.R. A single amino acid substitution abolishes the heterogeneity of chimeric mouse/human (IgG4) antibody. Mol. Immunol. 1993, 30, 105-108. [CrossRef]

36. Goldberg, A.; Geppert, T.; Schiopu, E.; Frech, T.; Hsu, V.; Simms, R.W.; Peng, S.L.; Yao, Y.; Elgeioushi, N.; Chang, L.; et al. Dose-escalation of human anti-interferon-alpha receptor monoclonal antibody medi-546 in subjects with systemic sclerosis: A phase 1, multicenter, open label study. Arthritis Res. Ther. 2014, 16, R57. [CrossRef] [PubMed]

37. Edelman, G.M.; Cunningham, B.A.; Gall, W.E.; Gottlieb, P.D.; Rutishauser, U.; Waxdal, M.J. The covalent structure of an entire gammaG immunoglobulin molecule. Proc. Natl. Acad. Sci. USA 1969, 63, 78-85. [CrossRef] [PubMed]

38. Kabat, E.A.; National Institutes of Health (U.S.) Office of the Director. Sequences of Proteins of Immunological Interest, 5th ed.; DIANE Publishing: Collingdale, PA, USA, 1991.

39. Lefranc, M.P.; Giudicelli, V.; Ginestoux, C.; Bodmer, J.; Muller, W.; Bontrop, R.; Lemaitre, M.; Malik, A.; Barbie, V.; Chaume, D. Imgt, the international immunogenetics database. Nucleic Acids Res. 1999, 27, $209-212$. [CrossRef] [PubMed]

40. Matsumiya, S.; Yamaguchi, Y.; Saito, J.; Nagano, M.; Sasakawa, H.; Otaki, S.; Satoh, M.; Shitara, K.; Kato, K. Structural comparison of fucosylated and nonfucosylated Fc fragments of human immunoglobulin G1. J. Mol. Biol. 2007, 368, 767-779. [CrossRef] [PubMed]

41. Scallon, B.J.; Moore, M.A.; Trinh, H.; Knight, D.M.; Ghrayeb, J. Chimeric anti-TNF- $\alpha$ monoclonal antibody cA2 binds recombinant transmembrane TNF- $\alpha$ and activates immune effector functions. Cytokine 1995, 7, 251-259. [CrossRef] [PubMed]

42. Scallon, B.; McCarthy, S.; Radewonuk, J.; Cai, A.; Naso, M.; Raju, T.S.; Capocasale, R. Quantitative in vivo comparisons of the Fc gamma receptor-dependent agonist activities of different fucosylation variants of an immunoglobulin G antibody. Int. Immunopharmacol. 2007, 7, 761-772. [CrossRef] [PubMed]

43. Smith, P.; DiLillo, D.J.; Bournazos, S.; Li, F.; Ravetch, J.V. Mouse model recapitulating human Fcgamma receptor structural and functional diversity. Proc. Natl. Acad. Sci. USA 2012, 109, 6181-6186. [CrossRef] [PubMed]

44. Bevaart, L.; Jansen, M.J.; van Vugt, M.J.; Verbeek, J.S.; van de Winkel, J.G.; Leusen, J.H. The high-affinity IgG receptor, FcgammaRI, plays a central role in antibody therapy of experimental melanoma. Cancer Res. 2006, 66, 1261-1264. [CrossRef] [PubMed]

45. Boross, P.; Jansen, J.H.M.; van Tetering, G.; Nederend, M.; Brandsma, A.; Meyer, S.; Torfs, E.; van den Ham, H.-J.; Meulenbroek, L.; de Haij, S.; et al. Anti-tumor activity of human IgG1 anti-gp75 TA99 mab against B16F10 melanoma in human FcgammaRI transgenic mice. Immunol. Lett. 2014, 160, 151-157. [CrossRef] [PubMed]

46. Garber, E.; Demarest, S.J. A broad range of Fab stabilities within a host of therapeutic IgGs. Biochem. Biophys. Res. Commun. 2007, 355, 751-757. [CrossRef] [PubMed] 
47. Ferrara, C.; Grau, S.; Jager, C.; Sondermann, P.; Brunker, P.; Waldhauer, I.; Hennig, M.; Ruf, A.; Rufer, A.C.; Stihle, M.; et al. Unique carbohydrate-carbohydrate interactions are required for high affinity binding between FcgammaRIII and antibodies lacking core fucose. Proc. Natl. Acad. Sci. USA 2011, 108, 12669-12674. [CrossRef] [PubMed]

48. Mimoto, F.; Katada, H.; Kadono, S.; Igawa, T.; Kuramochi, T.; Muraoka, M.; Wada, Y.; Haraya, K.; Miyazaki, T.; Hattori, K. Engineered antibody Fc variant with selectively enhanced Fc $\gamma$ RIIb binding over both Fc $\gamma$ RIIa(R131) and Fc $\gamma$ RIIa(H131). Protein Eng. Des. Sel. 2013, 26, 589-598. [CrossRef] [PubMed]

49. Teplyakov, A.; Zhao, Y.; Malia, T.J.; Obmolova, G.; Gilliland, G.L. IgG2 Fc structure and the dynamic features of the IgG CH2-CH3 interface. Mol. Immunol. 2013, 56, 131-139. [CrossRef] [PubMed]

50. Davies, A.M.; Rispens, T.; Ooijevaar-de Heer, P.; Gould, H.J.; Jefferis, R.; Aalberse, R.C.; Sutton, B.J. Structural determinants of unique properties of human IgG4-Fc. J. Mol. Biol. 2014, 426, 630-644. [CrossRef] [PubMed]

51. Kiyoshi, M.; Caaveiro, J.M.; Kawai, T.; Tashiro, S.; Ide, T.; Asaoka, Y.; Hatayama, K.; Tsumoto, K. Structural basis for binding of human IgG1 to its high-affinity human receptor FcgammaRI. Nat. Commun. 2015, 6, 6866. [CrossRef] [PubMed]

52. Desjarlais, J.R.; Lazar, G.A.; Zhukovsky, E.A.; Chu, S.Y. Optimizing engagement of the immune system by anti-tumor antibodies: An engineer's perspective. Drug Discov. Today 2007, 12, 898-910. [CrossRef] [PubMed]

53. Nimmerjahn, F.; Ravetch, J.V. Fc $\gamma$ receptors: Old friends and new family members. Immunity 2006, 24, 19-28. [CrossRef] [PubMed]

54. Nimmerjahn, F.; Ravetch, J.V. The antiinflammatory activity of IgG: The intravenous IgG paradox. J. Exp. Med. 2007, 204, 11-15. [CrossRef] [PubMed]

55. Nimmerjahn, F.; Ravetch, J.V. Fc $\gamma$ receptors as regulators of immune responses. Nat. Rev. Immunol. 2008, 8, 34-47. [CrossRef] [PubMed]

56. Cole, M.S.; Stellrecht, K.E.; Shi, J.D.; Homola, M.; Hsu, D.H.; Anasetti, C.; Vasquez, M.; Tso, J.Y. Hum291, a humanized anti-CD3 antibody, is immunosuppressive to $\mathrm{T}$ cells while exhibiting reduced mitogenicity in vitro. Transplantation 1999, 68, 563-571. [CrossRef] [PubMed]

57. Nimmerjahn, F.; Ravetch, J.V. Analyzing antibody-Fc receptor interactions. Methods Mol. Biol. 2008, 415, 151-162. [PubMed]

58. Davies, A.M.; Jefferis, R.; Sutton, B.J. Crystal structure of deglycosylated human IgG4-Fc. Mol. Immunol. 2014, 62, 46-53. [CrossRef] [PubMed]

59. Hara, I.; Takechi, Y.; Houghton, A.N. Implicating a role for immune recognition of self in tumor rejection: Passive immunization against the brown locus protein. J. Exp. Med. 1995, 182, 1609-1614. [CrossRef] [PubMed]

60. Firan, M.; Bawdon, R.; Radu, C.; Ober, R.J.; Eaken, D.; Antohe, F.; Ghetie, V.; Ward, E.S. The MHC class I-related receptor, FCRn, plays an essential role in the maternofetal transfer of $\gamma$-globulin in humans. Int. Immunol. 2001, 13, 993-1002. [CrossRef] [PubMed]

61. Stubenrauch, K.; Wessels, U.; Lenz, H. Evaluation of an immunoassay for human-specific quantitation of therapeutic antibodies in serum samples from non-human primates. J. Pharm. Biomed. Anal. 2009, 49, 1003-1008. [CrossRef] [PubMed]

62. Labrijn, A.F.; Meesters, J.I.; de Goeij, B.E.; van den Bremer, E.T.; Neijssen, J.; van Kampen, M.D.; Strumane, K.; Verploegen, S.; Kundu, A.; Gramer, M.J.; et al. Efficient generation of stable bispecific IgG1 by controlled Fab-arm exchange. Proc. Natl. Acad. Sci. USA 2013, 110, 5145-5150. [CrossRef] [PubMed]

63. Scallon, B.; Cai, A.; Solowski, N.; Rosenberg, A.; Song, X.Y.; Shealy, D.; Wagner, C. Binding and functional comparisons of two types of tumor necrosis factor antagonists. J. Pharm. Exp. Ther. 2002, 301, 418-426. [CrossRef]

64. Roopenian, D.C.; Christianson, G.J.; Sproule, T.J. Human FcRn transgenic mice for pharmacokinetic evaluation of therapeutic antibodies. Methods Mol. Biol. 2010, 602, 93-104. [PubMed]

65. Proetzel, G.; Wiles, M.V.; Roopenian, D.C. Genetically engineered humanized mouse models for preclinical antibody studies. BioDrugs Clin. Immunother. Biopharm. Gene Ther. 2014, 28, 171-180. [CrossRef] [PubMed]

66. Proetzel, G.; Roopenian, D.C. Humanized FcRn mouse models for evaluating pharmacokinetics of human IgG antibodies. Methods 2014, 65, 148-153. [CrossRef] [PubMed] 
67. Stein, C.; Kling, L.; Proetzel, G.; Roopenian, D.C.; de Angelis, M.H.; Wolf, E.; Rathkolb, B. Clinical chemistry of human FcRn transgenic mice. Mamm. Genome Off. J. Int. Mamm. Genome Soc. 2012, 23, 259-269. [CrossRef] [PubMed]

68. Gautam, A.; Waldrep, J.C.; Densmore, C.L.; Koshkina, N.; Melton, S.; Roberts, L.; Gilbert, B.; Knight, V. Growth inhibition of established B16-F10 lung metastases by sequential aerosol delivery of p53 gene and 9-nitrocamptothecin. Gene Ther. 2002, 9, 353-357. [CrossRef] [PubMed]

69. Bernett, M.J.; Dahiyat, B.; Desjarlais, J.; Lazar, G.A.; Moore, G.L. Antibodies with Modified Isoelectric Points and Immunofiltering. US 14/853,622, 10 March 2016.

70. Jacobs, S. Stabilized Fibronectin Domain Compositions, Methods and Uses. EP20110775616, 22 June 2016.

71. Leung, D.D.M.; Swanson, B.A.; Tang, Y.; Luan, P.; Witcher, D.R. Anti-Hepcidin Antibodies and Uses Thereof. EP20120172307, 28 November 2012.

72. Kabsch, W. Xds. Acta Crystallogr. Sect. D Biol. Crystallogr. 2010, 66, 125-132. [CrossRef] [PubMed]

73. McCoy, A.J.; Grosse-Kunstleve, R.W.; Adams, P.D.; Winn, M.D.; Storoni, L.C.; Read, R.J. Phaser crystallographic software. J. Appl. Crystallogr. 2007, 40, 658-674. [CrossRef] [PubMed]

74. Winn, M.D.; Ballard, C.C.; Cowtan, K.D.; Dodson, E.J.; Emsley, P.; Evans, P.R.; Keegan, R.M.; Krissinel, E.B.; Leslie, A.G.; McCoy, A.; et al. Overview of the CCP4 suite and current developments. Acta Crystallogr. Sect. D Biol. Crystallogr. 2011, 67, 235-242. [CrossRef] [PubMed]

75. Emsley, P.; Cowtan, K. Coot: Model-building tools for molecular graphics. Acta Crystallogr. Sect. D Biol. Crystallogr. 2004, 60, 2126-2132. [CrossRef] [PubMed]

76. Afonine, P.V.; Grosse-Kunstleve, R.W.; Chen, V.B.; Headd, J.J.; Moriarty, N.W.; Richardson, J.S.; Richardson, D.C.; Urzhumtsev, A.; Zwart, P.H.; Adams, P.D. Phenix.Model_vs_data: A high-level tool for the calculation of crystallographic model and data statistics. J. Appl. Crystallogr. 2010, 43, 669-676. [CrossRef] [PubMed]

77. Adams, P.D.; Afonine, P.V.; Bunkoczi, G.; Chen, V.B.; Davis, I.W.; Echols, N.; Headd, J.J.; Hung, L.W.; Kapral, G.J.; Grosse-Kunstleve, R.W.; et al. Phenix: A comprehensive python-based system for macromolecular structure solution. Acta Crystallogr. Sect. D Biol. Crystallogr. 2010, 66, 213-221. [CrossRef] [PubMed]

78. Bowers, K.J.; Chow, E.; Xu, H.; Dror, R.O.; Eastwood, M.P.; Gregersen, B.A.; Klepeis, J.L.; Kolossvary, I.; Moraes, M.A.; Sacerdoti, F.D.; et al. Scalable algorithms for molecular dynamics simulations on commodity clusters. In Proceedings of the 2006 ACM/IEEE Conference on Supercomputing ACM, Tampa, FL, USA, 11-17 November 2006.

79. Schrödinger. Available online: http:/ / www.schrodinger.com (accessed on 1 March 2016).

80. Robinson, G.W.Z.; Zhu, S.B.; Singh, S.; Evans, M.W. Water in Biology, Chemistry, and Physics: Experimental Overviews and Computational Methodologies; World Scientific: Singapore, 1996; p. 9.

81. Harder, E.; Damm, W.; Maple, J.; Wu, C.; Reboul, M.; Xiang, J.Y.; Wang, L.; Lupyan, D.; Dahlgren, M.K.; Knight, J.L.; et al. Opls3: A force field providing broad coverage of drug-like small molecules and proteins. J. Chem. Theory Comput. 2016, 12, 281-296. [CrossRef] [PubMed]

82. Liu, P.; Kim, B.; Friesner, R.A.; Berne, B.J. Replica exchange with solute tempering: A method for sampling biological systems in explicit water. Proc. Natl. Acad. Sci. USA 2005, 102, 13749-13754. [CrossRef] [PubMed]

(C) 2017 by the authors. Licensee MDPI, Basel, Switzerland. This article is an open access article distributed under the terms and conditions of the Creative Commons Attribution (CC BY) license (http://creativecommons.org/licenses/by/4.0/). 